\title{
The Cx43 Carboxyl-Terminal Mimetic Peptide $\alpha$ CT1 Protects Endothelial Barrier Function in a ZO1 Binding-Competent Manner
}

\author{
Randy E. Strauss ${ }^{1, *}$, Louisa Mezache ${ }^{2}$, Rengasayee Veeraraghavan ${ }^{2,3,4}$ and Robert G. Gourdie ${ }^{5,6,7, * \text { (D) }}$ \\ 1 Virginia Tech, Translational Biology Medicine and Health (TBMH) Program, Roanoke, VA 24016, USA \\ 2 Department of Biomedical Engineering, College of Engineering, The Ohio State University, \\ 460 Medical Center Dr., Rm 415A, IBMR, Columbus, OH 43210, USA; \\ mezache.2@buckeyemail.osu.edu (L.M.); veeraraghavan.12@osu.edu (R.V.) \\ 3 The Frick Center for Heart Failure and Arrhythmia, Davis Heart and Lung Research Institute, \\ College of Medicine, The Ohio State University Wexner Medical Center, Columbus, OH 43210, USA \\ 4 Department of Physiology and Cell Biology, College of Medicine, The Ohio State University, \\ Columbus, $\mathrm{OH} 43210$, USA \\ 5 Center for Heart and Reparative Medicine Research, Fralin Biomedical Research Institute at Virginia \\ Tech Carilion, Roanoke, VA 24016, USA \\ 6 Virginia Tech Carilion School of Medicine, Roanoke, VA 24016, USA \\ 7 Department of Biomedical Engineering and Mechanics, Virginia Polytechnic Institute and State University, \\ Blacksburg, VA 24060, USA \\ * Correspondence: randys@vt.edu (R.E.S.); gourdier@vtc.vt.edu (R.G.G.)
}

Citation: Strauss, R.E.; Mezache, L.; Veeraraghavan, R.; Gourdie, R.G. The Cx43 Carboxyl-Terminal Mimetic Peptide $\alpha$ CT1 Protects Endothelial Barrier Function in a ZO1 Binding-Competent Manner. Biomolecules 2021, 11, 1192. https:// doi.org/10.3390/biom11081192

Academic Editor: Maliha Zahid

Received: 16 July 2021

Accepted: 6 August 2021

Published: 12 August 2021

Publisher's Note: MDPI stays neutral with regard to jurisdictional claims in published maps and institutional affiliations.

Copyright: (C) 2021 by the authors Licensee MDPI, Basel, Switzerland. This article is an open access article distributed under the terms and conditions of the Creative Commons Attribution (CC BY) license (https:// creativecommons.org/licenses/by/ $4.0 /)$.
Abstract: The Cx43 carboxyl-terminus (CT) mimetic peptide, $\alpha \mathrm{CT} 1$, originally designed to bind to Zonula Occludens 1 (ZO1) and thereby inhibit Cx43/ZO1 interaction, was used as a tool to probe the role of $\mathrm{Cx} 43 / \mathrm{ZO} 1$ association in regulation of epithelial/endothelial barrier function. Using both in vitro and ex vivo methods of barrier function measurement, including Electric CellSubstrate Impedance Sensing (ECIS), a TRITC-dextran Transwell permeability assay, and a FITCdextran cardiovascular leakage protocol involving Langendorff-perfused mouse hearts, $\alpha \mathrm{CT} 1$ was found to protect the endothelium from thrombin-induced breakdown in cell-cell contacts. Barrier protection was accompanied by significant remodeling of the F-actin cytoskeleton, characterized by a redistribution of F-actin away from the cytoplasmic and nuclear regions of the cell, towards the endothelial cell periphery, in association with alterations in cellular chiral orientation distribution. In line with observations of increased cortical F-actin, $\alpha \mathrm{CT} 1$ upregulated cell-cell border localization of endothelial VE-cadherin, the tight junction protein Zonula Occludens 1 (ZO1), and the Gap Junction Protein (GJ) Connexin43 (Cx43). A ZO1 binding-incompetent variant of $\alpha \mathrm{CT} 1, \alpha \mathrm{CT} 1-\mathrm{I}$, indicated that these effects on barrier function and barrier-associated proteins, were likely associated with Cx43 $\mathrm{CT}$ sequences retaining ability to interact with $\mathrm{ZO} 1$. These results implicate the Cx43 CT and its interaction with ZO1, in the regulation of endothelial barrier function, while revealing the therapeutic potential of $\alpha \mathrm{CT} 1$ in the treatment of vascular edema.

Keywords: Cx43; Zonula Occludens 1; barrier function; tight junctions; adherens junctions; actin cytoskeleton; endothelial cells

\section{Introduction}

Barrier function is a vital mechanism characterized by the homeostatic exchange of substances between interior and exterior compartments of epithelial tissues, marked by apical and basolateral membrane domains, respectively [1]. Diseases associated with vascular barrier function disruption occur in the heart and other tissues, the functions of which critically depend upon a healthy blood circulation. These diseases include ischemia-reperfusion injury, coronary artery disease (CAD), stroke, acute respiratory distress syndrome (ARDS), 
chronic skin wounds such as diabetic foot ulcers as well as many other pathologies [2-9]. The vascular endothelial barrier, a specialized epithelial monolayer lining blood vessels, acts like a semi-permeable filter that regulates the exchange of cells, extracellular vesicles, plasma proteins, solutes, and fluids between the circulation and tissue $[9,10]$. Pathological stress triggers breakdown in these barrier properties, causing characteristic disruptions in cytoskeletal structure and junctional complexes at cell-cell contacts, including intercellular gap formation [11]. These changes can result in edematous buildup of fluid, ions and other solutes, as well as enhanced immune cell infiltration across multiple tissue types and disease processes [3,9].

Cellular structures involved in regulating barrier function include (1) the tight junction (TJ), which provides a gating mechanism that directly controls the exchange of substances across the paracellular space; (2) the adherens junction (AJ), which is critical for the establishment and maintenance of cell-cell adhesion; (3) the actin cytoskeleton, which controls the overall integrity of cell-cell contacts via mechanical push/pull forces; and (4) the gap junction (GJ), which allows for exchange of signaling molecules and ions between cells through connexin-based transcellular channels, in addition to providing close points of intercellular adhesion [12-14]. While initially conceived of as independent, these transcellular complexes were subsequently identified as sharing direct interactions with the tight junction scaffolding molecule, Zonula Occludens 1 (ZO1), which is thought to contribute to biochemical and biophysical crosstalk between their protein components $[12,13,15,16]$.

Findings have emerged over the last 20 years or more that gap junctional connexins, especially the most studied isoform, Connexin 43 (Cx43), influences barrier function and permeability [17]. There is also growing appreciation that this may involve both channeldependent and independent functions of Cx43, including via effects on intercellular communication, membrane permeability, cell-cell contact arrangements and cytoskeletal dynamics, junction assembly, cell polarity, and transcriptional regulation [18-22]. While mounting evidence suggests that $\mathrm{C} \times 43$-based channel activity can modulate barrier function changes under pathological stress conditions, the channel-independent role of $\mathrm{C} \times 43$ in barrier modulation is less understood. The Cx43 carboxyl-terminus (CT) exhibits a well-characterized interaction with ZO1, specifically at its PDZ2 domain [23-25]. While the details of this structural interaction are well established, the functional consequences remain to be characterized. In this study, we examine the effects of short mimetic peptides based on the Cx43 $\mathrm{CT}$ sequence, with and without the capacity to interact with ZO1. Our results indicate that $\alpha \mathrm{CT} 1$, which incorporates the CT-most 9 amino acids of $\mathrm{Cx} 43$, protects endothelial cell barrier function in a ZO1 interaction-associated manner. $\alpha \mathrm{CT} 1$ is presently in clinical testing in humans for healing of normal and chronic skin wounds $[17,26]$. The barrier protective effect of $\alpha \mathrm{CT} 1$ is accompanied by marked changes in patterns of ZO1, VE-cadherin, $\mathrm{Cx} 43$, and actin cytoskeleton remodeling in peptide-treated cells. Taken together, our data suggest that modulation of actin-based inter- and intra-cellular push/pull forces may be a key aspect of the molecular mechanism of $\alpha \mathrm{CT} 1$ on barrier function, contributing to the mode of action of this therapeutic peptide in regulating tissue edema.

\section{Materials and Methods}

\subsection{Test Reagents}

Peptides biotin- $\alpha$ CT1 (biotin-RQPKIWFPNRRKPWKK-RPRPDDLEI), biotin- $\alpha$ CT1-I (biotin-RQPKIWFPNRRKPWKK RPRPDDLE), and biotin-ANT (biotin-RQPKIWFPNRRKPWK) were synthesized and quality checked for fidelity and purity using high-performance liquid chromatography and mass spectrometry (LifeTein, Hillsborough, NJ, USA). Thrombin was purchased from Millipore Sigma (Burlington, MA, USA, Cat: T7513).

\subsection{FITC-Dextran Extravasation}

Langendorff-perfused mouse hearts were perfused for 20 min with Tyrode's solution with or without $\alpha \mathrm{CT} 1(100 \mu \mathrm{M})$, followed by $40 \mathrm{~min}$ with thrombin $(1.5 \mathrm{U} / \mathrm{mL})$. FITCdextran $(10 \mathrm{mg} / \mathrm{mL})$ was added to the final $10 \mathrm{~mL}$ of perfusate. Perfused hearts were 
then cryopreserved as described above and extravasated FITC-dextran levels assessed by confocal microscopy (Nikon, Melville, NY, USA) of cryosections.

\subsection{Impedance Measurement Using ECIS}

The barrier integrity of HMEC-1 (CDC, Atlanta, GA, USA) was measured using ECIS Z Theta system (Applied Biophysics, Troy, NY, USA). HMEC-1 monolayers with a seeding density of $7.50 \times 10^{4}$ cells $/ \mathrm{cm}^{2}$ were grown to confluence $(24-72 \mathrm{~h}$ ) on collagen I-coated $8 \mathrm{~W} \mathrm{10E}+$ electrodes. After cell sedimentation and attachment to the electrode surface within $30 \mathrm{~min}$ at room temperature, the 8-well arrays were placed inside the ECIS ${ }^{\circledR}$ device for impedance monitoring. All ECIS ${ }^{\circledR}$ measurements were analyzed at an Alternating Current (AC) frequency of $32 \mathrm{kHz}$, which was identified as the most sensitive frequency for this cell type (e.g., frequency at which maximum difference between cell-containing and cell-free measurements was achieved), each well measured every 2-4 min. At $1 \mathrm{~h}$ prior to treatment, media were exchanged with $360 \mu \mathrm{L}$ fresh media. Test reagents were diluted in prewarmed medium. A volume of $20 \mu \mathrm{L}$ peptide/media solution $(\alpha \mathrm{CT} 1, \alpha \mathrm{CT} 1-\mathrm{I}$, antennapedia sequence (ANT)) was added to a final concentration of $100 \mu \mathrm{M}$. Cells were incubated in peptide for $1 \mathrm{~h}$, then $20 \mu \mathrm{L}$ thrombin/Fetal Bovine Serum (FBS)-free media solution was added to a final concentration of $0.5 \mathrm{U} / \mathrm{mL}$. Approximately $5 \mathrm{~min}$ following thrombin addition, peptide-induced barrier function protection was calculated as the percentage of barrier protection from thrombin disruption $=[(\mathrm{ohmic}$ resistance peptideohmic resistance of thrombin)/ (ohmic resistance thrombin - ohmic resistance vehicle control) $] \times 100 \%$. The effects of peptides alone on barrier function were calculated as the change in ohmic resistance compared to vehicle control (ohmic resistance peptide-ohmic resistance vehicle).

\subsection{Macromolecular Permeability (MP)}

Macromolecular permeability (MP) filter inserts (pore size $0.4 \mu \mathrm{m}, 12 \mathrm{~mm}$ diameter) (Falcon, Corning, NY, USA; Cat: 353095) were coated with collagen I (Corning, NY, USA; Cat: 354246$)$ at $2 \mu \mathrm{g} / \mathrm{mL}$ in $0.02 \mathrm{~N}$ acetic acid. Subsequently, the lower compartments of $24 \mathrm{~W}$ Transwell chambers (Falcon, Corning, NY, USA; Cat: 353504,) were filled with $700 \mu \mathrm{L}$ Human Microvascular Endothelial Cell (HMEC-1) media. HMEC-1 cells suspended in $300 \mu \mathrm{L}$ media $\left(7.50 \times 10^{4} \mathrm{cells} / \mathrm{cm}^{2}\right)$ were seeded on the upper compartment. They were grown to confluence (48-96 h). Cells were treated as indicated in the ECIS experiments (see above). At $55 \mathrm{~min}$ after peptide addition, $4 \mu \mathrm{L} 100 \mathrm{mg} / \mathrm{mL}$ Tetramethylrhodamine isothiocyanate (TRITC)-dextran $/ \mathrm{H}_{2} 0$ solution was added to wells. A volume of 150 microliters of basolateral media was collected for time 0 . Thrombin was added to experimental wells to final concentration of $1.5 \mathrm{U} / \mathrm{mL}, 5 \mathrm{~min}$ after the application of FITC-dextran. The $150 \mu \mathrm{L}$ samples were taken after 5, 10, 15, 20 min from the lower compartment. The removed volume was immediately replaced by fresh medium. To evenly disperse TRITC-dextran within the media, Transwell plates were gently shaken. Fluorescence (ex: $485 \mathrm{~nm}$; em: $535 \mathrm{~nm}$ ) was measured with a fluorescence plate reader. Data are expressed as relative changes in fluorescence compared to vehicle permeability. $P(\mathrm{~cm} / \mathrm{s})$ was calculated by the following equation [27].

$$
P=\frac{\left[C(t)-C\left(t_{0}\right)\right] \cdot V}{A \cdot t \cdot C_{0}}
$$

$\mathrm{C}(\mathrm{t})$ is the concentration $(\mu \mathrm{g} / \mathrm{mL})$ of TRITC-dextran in the samples that were taken from the lower compartment after 5, 10, 15, $20 \mathrm{~min}$; $\mathrm{C}\left(t_{0}\right)$ is the TRITC dextran concentration $(\mu \mathrm{g} / \mathrm{mL})$ of the samples taken after $0 \mathrm{~min}$; $\mathrm{t}$ is the duration of the flux $(\mathrm{s}) ; V$ is the volume $\left(\mathrm{cm}^{3}\right)$ in the lower compartment; A is the surface of the Transwell membrane $\left(\mathrm{cm}^{2}\right)$; and $C_{0}$ is the initial concentration $(\mu \mathrm{g} / \mathrm{mL})$ of the tracer on the donor side. The concentration of TRITC-dextran in each sample was determined by reference to a TRITC-dextran standard curve. 


\subsection{Proximity Ligation Assay}

The peptide/ZO1 interaction was detected in situ using the Duolink secondary antibodies and detection kit (Sigma, St Louis, MO, USA; Cat: 92002, 92004) according to manufacturer instructions. Primary antibodies against Cx43 (South San Francisco, CA, USA; Cat: SC6560) and biotin (Invitrogen, Carlsbad, CA, USA; Cat: 617-300) were applied under standard conditions. Duolink secondary antibodies against the primary antibodies were then added. These secondary antibodies were provided as conjugates to oligonucleotides that when within close proximity $(<40 \mathrm{~nm} ;$ [28]) were ligated together in Duolink Ligation Solution. Finally, polymerase was added to trigger closed circle rolling amplification (which amplified any existing closed circles) and detection was achieved with complementary, fluorescently labeled oligonucleotides.

Confocal images were acquired on a TCS SP8 laser scanning confocal microscope (LSCM) equipped with a $63 \times / 1.4$ numerical aperture (NA) oil objective (Leica, Buffalo Grove, IL, USA). Image processing and quantitative image analysis of Duolink signal were performed using Cell Profiler (MIT, Cambridge, MA, USA). An intensity threshold was applied, then object clusters between 2 and 50 pixels in diameter were identified as Duolink Objects, then compared to original signal for validation. These Duolink objects were then counted and normalized to the number of nuclei in the images, and these values were normalized again to the no peptide control.

\subsection{Immunostaining and Quantitative Image Analysis}

For peptide uptake experiments (Figure 1), Cx43-deficient Madin-Darby Canine Kidney Cells (MDCK) monolayers were treated with peptide for $1 \mathrm{~h}$, then cells were washed with Dulbecco's phosphate-buffered saline (DPBS) w/ $\mathrm{Ca}^{2+}$ and $\mathrm{Mg}^{2+}$, then fixed with $4 \%$ paraformaldehyde. The biotin portion of the peptides were labeled with Streptavidin, Alexa Fluor 647 (Invitrogen, Carlsbad, CA, USA; Cat: S21374). ZO1 was detected with Rb A-ZO1 (Zymed, South San Francisco, CA, USA; Cat: 61-7300) and Chicken A-Rb 488 (Life Technology, Carlsbad, CA, USA; Cat: A21441). Actin was labeled in Human Dermal Microvascular Endothelial Cells (HDMEC), grown to confluence on Transwell filters (Promocell, Heidelberg, Germany) by Alexa Fluor 647 phalloidin (Invitrogen, Carlsbad, CA, USA; Cat: A22287) (Section 3.2). Colocalization analysis was performed by isolated border ZO1 pixels and calculation Pearson correlation coefficient with peptide biotin signal. For the distribution of cell orientations in HDMECs, absolute skewness measurements were calculated as the absolute value of $\mathrm{g} 1=$ the average value of $\mathrm{z}^{3}$, where $\mathrm{z}$ is the familiar $\mathrm{z}$-score, $\mathrm{z}=(x-\bar{x}) / \sigma$, where $\mathrm{x}$ is the individual cell angle with respect to a $0^{\circ}$ angle reference axis. Quantitative Image Analysis of F-actin, VE-cadherin, ZO1, and Cx43 was performed using Cell Profiler (MIT, Cambridge, MA, USA) [29]. For a given cell within a monolayer selected at random to be quantified, a mask based on immunolabeling signals was created in Cell Profiler. Then, the radial distribution of relative F-actin, Cx43, ZO1 or VE-cadherin labeling levels were measured from the cell center to the cell border in 20 successive sub-regions. The sub-regions were each $\sim 1-1.5 \mu \mathrm{m}$ in width. Normalized fractional intensity for each sub-region was calculated as a fraction of total intensity normalized by fraction of pixels at a given radius. Means at each cell location were then estimated in R Studio [30] by employing a General Linear Model with Random Effects to account for the variability within each cell location. 95\% confidence intervals for each treatment mean at each cell location were then calculated.

\subsection{Statistics}

All data from at least three independent experiments are presented as the mean \pm standard error of the mean. Statistical significance was evaluated using GraphPad Prism (version 8.3, GraphPad Prism, San Diego, CA, USA) and assessed by one-way Analysis of variance (ANOVA) and post hoc tests properly corrected for multiple comparisons where applicable. For protein radial distribution statistics, a General Linear Model with Random Effects was utilized in R Studio [30] and estimated means from the model were 
calculated with $95 \%$ confidence intervals. Significant differences between treatments groups and thrombin treatment alone were reported in Supplementary Tables S1 and S2. A Kolmogorov-Smirnov (KS) test on cell orientation data was performed to confirm the significance of these findings (data not shown). Significant differences were assumed at $p \leq 0.05$.
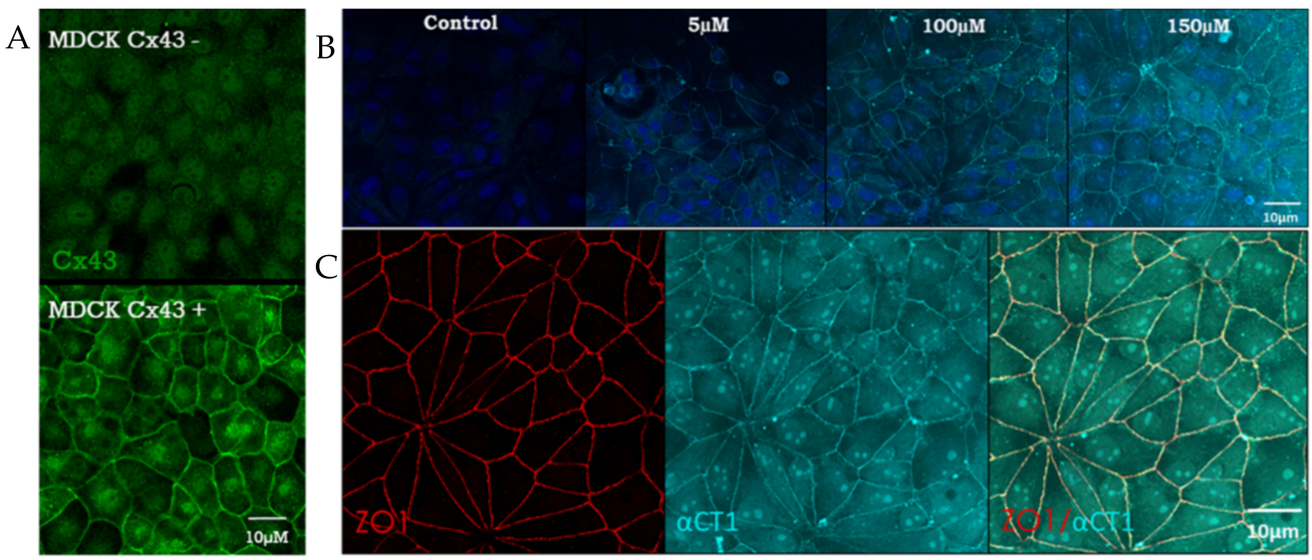

Figure 1. Cx43 CT mimetic peptide, $\alpha \mathrm{CT} 1$, colocalizes with ZO1 inside Cx43-deficient MDCK cells. (A) Representative confocal images of Cx43-deficient and Cx43-expressing MDCK cells. (B) Representative confocal images of the dose-dependent uptake of fluorescent streptavidin-labeled, biotinylated $\alpha \mathrm{CT} 1(0,5,100,150 \mu \mathrm{M})$ inside Cx43-deficient MDCK cells, fixed at $1 \mathrm{~h}$ post-incubation of peptide. (C) Representative confocal images of ZO1 $+\alpha \mathrm{CT} 1$, combined into a merged image to highlight colocalization (yellow).

\section{Results}

3.1. $\alpha$ CT1 Requires a CT Isoleucine to Associate with ZO1 at Borders between MDCK Cells

The $\alpha \mathrm{CT} 1$ peptide consists of the CT-most 9 amino acids of Cx43: Arg-Pro-Arg-ProAsp-Asp-Leu- Glu-Iso or RPRPDDLEI, includes a 16 amino acid N-terminal antennapedia sequence (ANT) and typically has an N-terminal biotin tag [30]. The last four amino acids of $\alpha \mathrm{CT} 1$ (DLEI) mimic the class II PDZ-binding motif of Cx43, which has been shown to mediate interactions with the second of the three PDZ (PDZ2) domains of the tight junction protein, ZO1 [30]. Deletion of the CT isoleucine of this motif abrogates interaction of $\alpha \mathrm{CT} 1$ with ZO1 PDZ2, as is the case with the ZO1 binding-incompetent $\alpha \mathrm{CT} 1-\mathrm{I}$ variant used in this, as well as our previous work on the molecular mechanism Cx43 CT peptides in mitigating cardiac ischemia-reperfusion injury [31]. In these studies, we demonstrated that in addition to interacting with ZO1, $\alpha \mathrm{CT} 1$ has the capacity to interact with $\mathrm{Cx} 43 \mathrm{CT}$ itself.

Using Electric Cell-Substrate Impedance Sensing (ECIS) we previously reported that $\alpha \mathrm{CT} 1$ abrogates EGTA-induced loss of barrier function in retinal pigment epithelial monolayers [31]. Follow-up ECIS experiments in the present study indicated that Cx43-deficient Madin-Darby Canine Kidney (MDCK) cell cultures were similarly protected by $\alpha \mathrm{CT} 1$, but not $\alpha \mathrm{CT} 1-\mathrm{I}$, from a Ca ${ }^{2+}$ chelating, EGTA -treatment. The addition of $100 \mu \mathrm{M} \alpha \mathrm{CT} 1$, 5 min after $\mathrm{Ca}^{2+}$ chelation with $2 \mathrm{mM}$ EGTA, produced barrier function recovery beyond that observed with the control peptides, $\alpha \mathrm{CT} 1-\mathrm{I}$, and the cell penetration sequence alone, antennapedia (ANT) (Supplementary Figure S1).

These initial barrier function findings in MDCK cells demonstrated the barrier functionmodulating potential of the 9 amino acid (aa) CT-most sequence of Cx43. These observations further indicated that $\alpha \mathrm{CT} 1^{\prime}$ s mechanism of action likely involved ZO1 binding competency. To confirm that $\alpha \mathrm{CT} 1$ interacts with ZO1 inside the cell, $\alpha \mathrm{CT} 1^{\prime}$ s association with the tight junction protein, ZO1, was investigated. We first examined $\alpha \mathrm{CT} 1$ uptake and distribution in MDCK cells using confocal microscopy. Cx43-negative MDCK cells (Figure 1A) were used in this analysis to reduce confounding binding of the $\alpha \mathrm{CT} 1$ and $\alpha \mathrm{CT} 1-\mathrm{I}$ to $\mathrm{Cx} 43$ itself, a characteristic of both peptides that we have demonstrated previously [32]. Consistent with results from HeLa cells [32], we observed robust antennapedia 
peptide-mediated uptake into MDCK cells. However, unlike HeLa cells, MDCK cells incubated with $\alpha \mathrm{CT} 1$ showed dense concentrations of peptide co-localized with ZO1 at cell-cell borders (Figure 1C). This pattern appeared to occur in a dose-responsive manner (Figure 1B), with signal intensity increasing with increasing concentrations of applied $\alpha \mathrm{CT} 1$ - from 5, to 100 to $150 \mu \mathrm{M}$. This distinctive co-localization is illustrated further in a 3Dvolumetric rendering in Figure 2B, where $\alpha \mathrm{CT} 1$, but not $\alpha \mathrm{CT} 1-\mathrm{I}$, can be seen to uniformly and intensely co-localize with ZO1 at an interface containing the tight junction belt between apposed cells. Quantitative analyses confirmed that $\alpha \mathrm{CT} 1$ colocalized with ZO1 at cell borders at significantly higher levels than the ZO1 binding-incompetent peptide $\alpha \mathrm{CT} 1-\mathrm{I}$, antennapedia (ANT) peptide alone (i.e., with no additional Cx43-related sequence), and vehicle controls, with no added peptide (Figure 2A,C). To further substantiate $\alpha \mathrm{CT} 1-\mathrm{ZO} 1$ association, we performed proximity ligation assays (Duolink) using antibodies against ZO1 and the biotin tags present on $\alpha \mathrm{CT} 1$ and $\alpha \mathrm{CT} 1-\mathrm{I}$ peptides. Punctate ZO1-biotin Duolink signals were significantly increased following incubation of cells with $\alpha \mathrm{CT} 1$, but largely attenuated following incubation with $\alpha$ CT1-I (Figure 2D,E). Taken together, these data suggested that $\alpha \mathrm{CT} 1$ associates in close proximity with ZO1 at Cx43-negative MDCK cell-cell borders, requiring a functional ZO1 PDZ2 domain-binding motif to maintain this pattern. These results were consistent with $\alpha \mathrm{CT} 1$ directly targeting and binding to ZO1 located at cell-to-cell junctions.

\section{2. $\alpha$ CT1 Inhibits Thrombin-Induced Disruption of Endothelial Barrier Function in a ZO1 Binding-Competent Manner}

Previous reports have demonstrated that the Cx43 mimetic, $\alpha \mathrm{CT} 1$, has cardioprotective properties in an ex vivo mouse model of global ischemia-reperfusion injury [33]. We considered that targeting of the coronary vasculature and effects on edema were an unexplored aspect of the mode of action of $\alpha \mathrm{CT} 1$ in cardioprotection. Breakdown in endothelial barrier function is a hallmark of several cardiac pathologies, including ischemia-reperfusion injury [6]. The barrier protective effects observed in the MDCK cells (Supplementary Figure S1) raised the possibility that $\alpha \mathrm{CT} 1$ might similarly protect barrier function within endothelial cells. To investigate the potential for $\alpha \mathrm{CT} 1$ to protect endothelial barrier function, we used ECIS to assess the barrier-modulating effect of $\alpha \mathrm{CT} 1$ and the ZO1 binding-incompetent control $\alpha$ CT1-I in microvascular endothelial cell monolayers. To this end, confluent HMEC-1 monolayers were grown on ECIS electrode arrays, treated with peptide $(100 \mu \mathrm{M})$ for $1 \mathrm{~h}$, then stimulated with thrombin $(1 \mathrm{U} / \mathrm{mL})$. Thrombin is a well-known barrier function disruptor and bona fide inflammatory mediator of ischemiareperfusion injury and other cardiac diseases [34]. ECIS indicated that pretreatment with $\alpha \mathrm{CT} 1$, but not $\alpha \mathrm{CT} 1-\mathrm{I}$, significantly attenuated barrier function disruption induced by thrombin in HMEC-1 monolayers (Figure 3A,B). Interestingly, we noted from ECIS records that a significant level of stabilization occurred prior to treatment with thrombin, during the one hour period in which cells were incubated with $\alpha \mathrm{CT} 1$ (Figure 3C). Again, a similar pretreatment effect was not observed for $\alpha$ CT1-I (Figure 3C). To further validate our results, we repeated the experiment using a second well-characterized assay of barrier integrity, a Transwell permeability assay based on the flux of a $4.5 \mathrm{kDa}$ TRITC dextran permeability tracer across the monolayer (Figure 4). In line with the ECIS data, $\alpha$ CT1 pretreatment significantly blocked hyperpermeability to the tracer following exposure to thrombin-at the 10 min time point of maximum disruption (Figure 4B), as indicated from initial time course experiments (Figure 4A). By contrast, $\alpha$ CT1-I demonstrated no barrier protecting effect. Based on these data, we concluded that pretreatment with $\alpha \mathrm{CT} 1$ was sufficient to maintain endothelial barrier in the context of thrombin-induced disruption, whereas the ZO1 binding-incompetent variant peptide $\alpha$ CT1-I was unable to mediate a similar protective effect. 

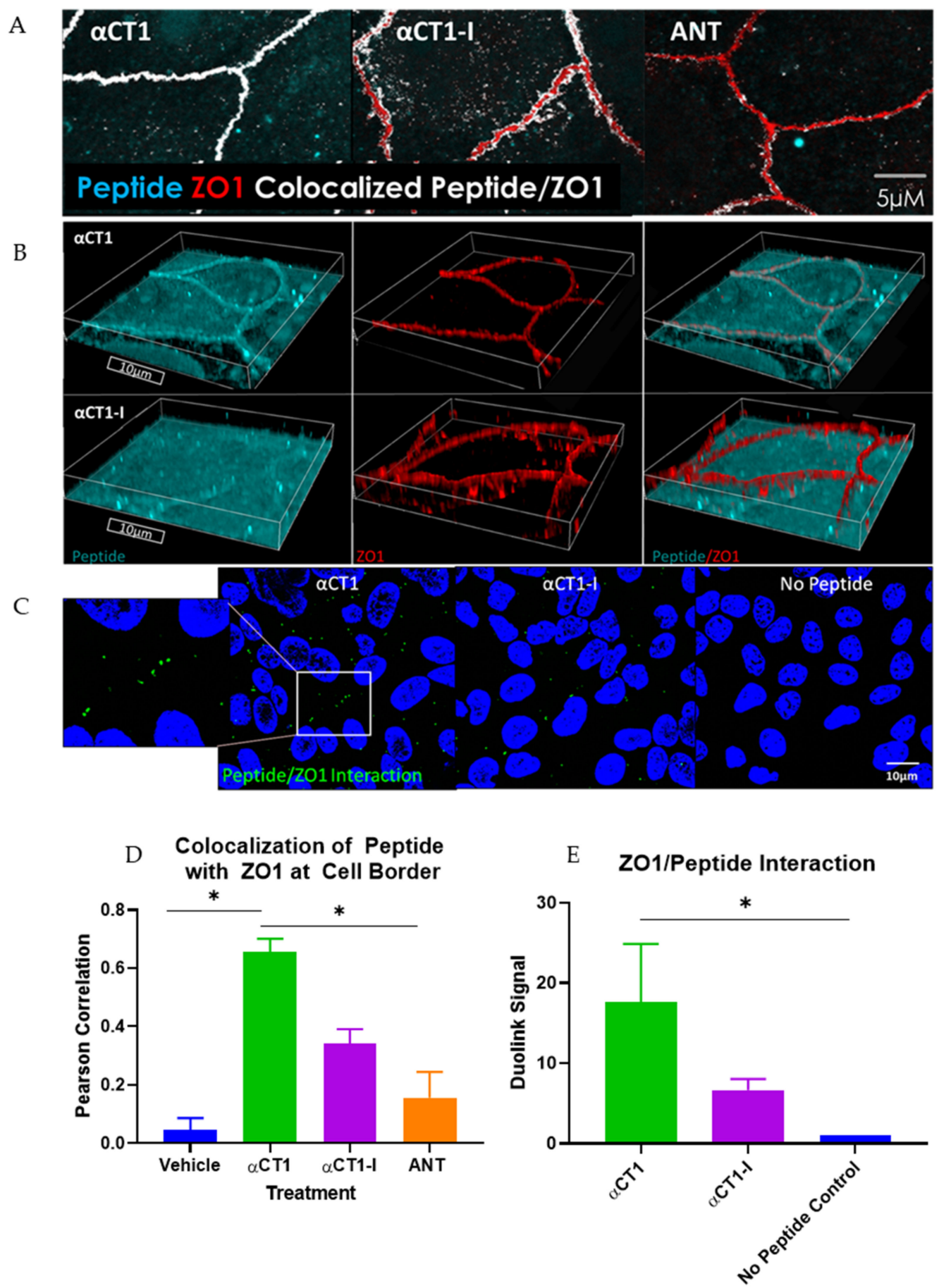

Figure 2. $\alpha \mathrm{CT} 1$ requires its terminal isoleucine to associate with $\mathrm{ZO} 1$ inside $\mathrm{Cx} 43$-deficient MDCK cells. (A) Representative confocal images of colocalization (white) between $\alpha \mathrm{CT} 1$ and ZO1 bindingdeficient control, $\alpha$ CT1-I, and cell penetration sequence control, antennapedia (ANT). (B) Representative volumetric 3D confocal image renderings of border localization of $\alpha \mathrm{CT} 1 \mathrm{vs.} \alpha \mathrm{CT} 1-\mathrm{I}$. (C) Representative confocal images of the Duolink interaction between peptides and ZO1. Green spots represent points of interaction. (D) Quantification of colocalization between the peptides and ZO1, as determined by Pearson Correlation analysis. (E) Quantification of the Duolink interaction between the peptides and ZO1. ${ }^{*} p<0.05$ vs. controls; $N=3$. 


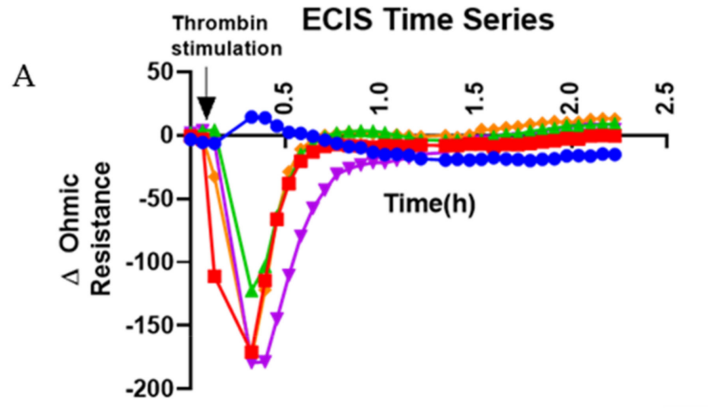

ECIS Barrier Function

B

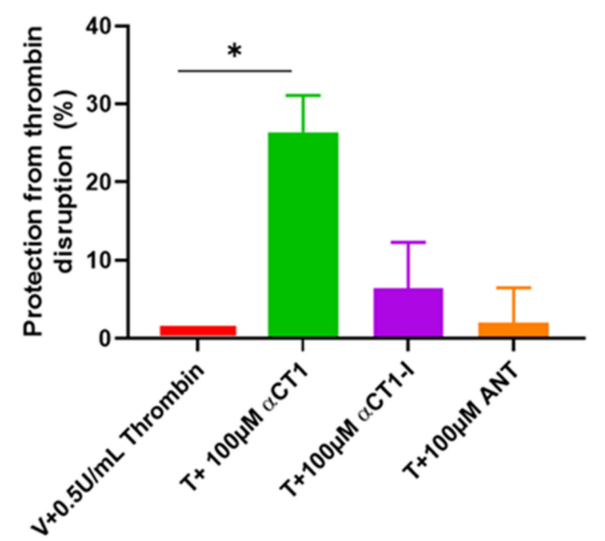

$\rightarrow$ Vehicles

$\rightarrow$ V+Thrombin $1.5 \mathrm{U} / \mathrm{mL}$

$\pm 100 \mu \mathrm{M} \alpha \mathrm{CT} 1+\mathrm{T}$

$* 100 \mu \mathrm{M} \alpha \mathrm{CT} 1-\mathrm{I}+\mathrm{T}$

$\rightarrow 100 \mu \mathrm{MANT}+\mathrm{T}$

Figure 3. $\alpha \mathrm{CT} 1$ requires ZO1 binding competency to protect the endothelial barrier from thrombininduced disruption measured by Electric Cell-Substrate Impedance Sensing (ECIS) in HMEC-1 cell monolayers. (A) Representative ECIS time series showing peptide-induced barrier function changes following thrombin treatment. Each data point represents the change in ohmic resistance from individual treatment baselines, collected at approx. 4 min intervals. (B) Approximately 5 min following thrombin addition, peptide-induced barrier function protection was calculated as the percentage of barrier protection from thrombin disruption (C) At $1 \mathrm{~h}$ peptide incubation, prior to thrombin treatment, the effects of peptides on barrier function were calculated as the change in ohmic resistance compared to vehicle control. ${ }^{* *} p<0.01 * p<0.05$ vs. controls; $N=3-5$.

A

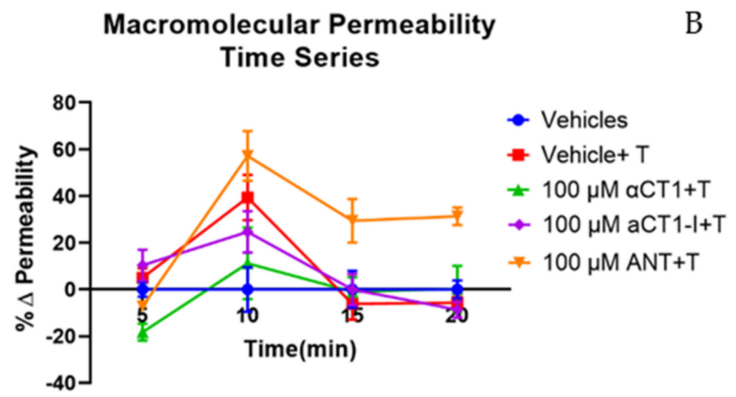

Macromolecular Permeability

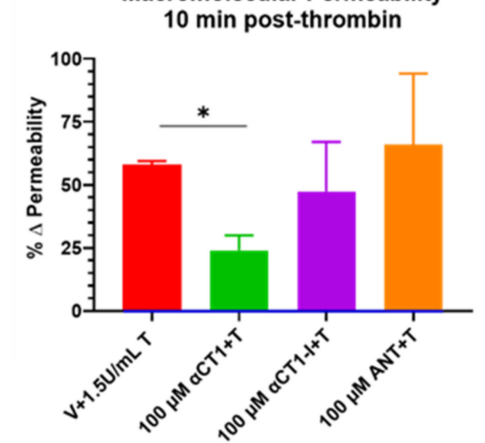

Figure 4. $\alpha \mathrm{CT} 1$ requires $\mathrm{ZO} 1$ binding competency to prevent thrombin-induced hyperpermeability in HMEC-1 cell monolayers. (A) Representative time course of macromolecular flux to $4.5 \mathrm{kDa}$ FITC-dextran across the endothelial monolayer, from the top (apical) to the bottom (basolateral) compartment of Transwell chambers. The percentage change in absolute permeability was calculated from fluorescent readings of samples taken from the bottom compartment at 5, 10, 15, and 20 min postthrombin stimulation. Measurements at each time point were normalized to vehicle control. (B) The change in permeability at the time point of maximum thrombin disruption (10 $\mathrm{min})$, normalized to vehicle control, were averaged across experiments. ${ }^{*} p<0.05$ vs. Vehicle control; $N=4$. 


\section{3. $\alpha$ CT1 Prevents Thrombin-Induced Changes in Endothelial F-Actin and VE-Cadherin Distribution in a ZO1 Binding-Competent Manner}

The mode of action of thrombin in disrupting barrier function is thought, in large part, to occur via its effects on the actin cytoskeleton and VE-cadherin [35,36]. Furthermore, a previous collaborative report demonstrated that $\alpha \mathrm{CT} 1$ produces significant changes to the actin cytoskeleton in brain endothelial cells, via a ZO1 PDZ2 interaction [37]. Therefore, HMEC-1 cells grown on solid substrates were immunolabeled for F-actin and VE-cadherin following a similar treatment protocol described for ECIS barrier function experiments, then fluorescent signals imaged using confocal microscopy.

We used this approach, together with a high-throughput quantitative image analysis software, Cell Profiler [29], to quantify changes in the cellular distribution of F-actin and VE-cadherin in our thrombin/peptide treatment model. Initial observations showed that untreated control HMEC-1 cells grown in monolayers exhibited thin, well-delineated bands of cortical actin marking the boundaries of cells, consistent with intact barrier function, as well as isolated fibers stretching across the cytoplasm of the cell (Figure 5). Thrombin treatment attenuated this sharp F-actin border, causing cells to form densely packed fibrous sheets of stress fibers that stretched across the cell, either through the center of the cell or just outside the cell center, in a manner consistent with cytoskeletal structures commonly linked to endothelial barrier function disruption in the literature (e.g., Figure 5). Thrombin also increased the formation of intercellular gaps. The thrombin-induced effects on F-actin at 5 min post-thrombin stimulation observed here are consistent with previous reports [38,39]. As for VE-cadherin, thrombin attenuated the sharp, linear VE-cadherin signal at the cell border, while simultaneously reducing concentrations of signal towards the center of the cell (Figure 5).

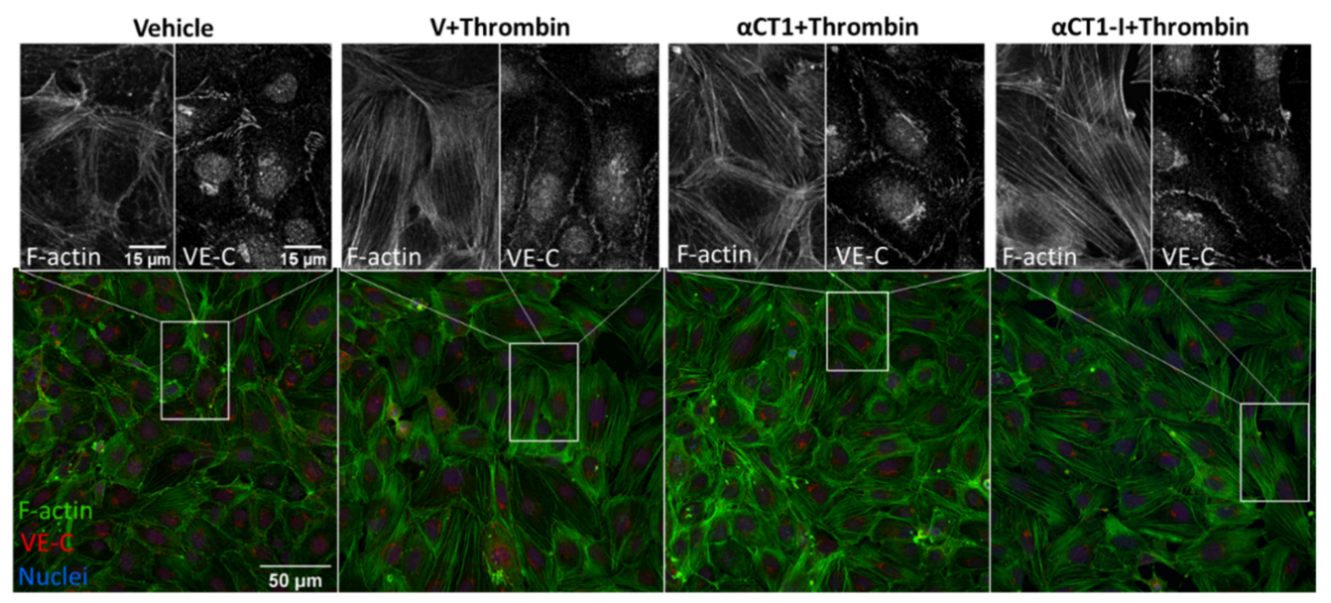

Figure 5. $\alpha \mathrm{CT} 1$ inhibits thrombin-induced shift in endothelial F-actin and VE-cadherin distribution in HMEC-1 cell monolayers. Representative confocal images of F-actin and VE-cadherin in $100 \mu \mathrm{M}$ labeling in peptide-treated, HMEC-1 cells, fixed $5 \mathrm{~min}$ after thrombin addition to the media. Zoomed sections show representative treatment-induced F-actin and VE-cadherin changes.

To quantify these changes, normalized intensities of F-actin and VE-cadherin immunolabeling were measured at 20 successive equivalently spaced intervals from the nucleus to the peripheral border of cells in the different treatment groups, as detailed in methods (see diagram in Figure 6A). Statistically significant differences in the cellular distribution of F-actin and VE-cadherin between the treatment conditions compared to thrombin alone are displayed in Figure 6 and in Supplemental Table S1. Overall, F-actin distribution increased more or less linearly from the cell nucleus outward to the cell periphery, peaking in mean fractional intensity near the cell periphery (Figure 6A). VE-cadherin distribution showed an opposite trend, though with an upward inflection in fractional intensity in region 17, located just a few radii inward from cell borders. Importantly, $\alpha \mathrm{CT} 1$, but not $\alpha \mathrm{CT} 1-\mathrm{I}$, pretreatment inhibited the thrombin-induced changes in F-actin morphology, consistent 
with barrier function effects described previously (Figure 6B). This $\alpha \mathrm{CT} 1$-associated effect, compared to $\alpha \mathrm{CT} 1-\mathrm{I}$, was marked by a significant increase in the proportion of peripherally located cortical actin, simultaneous with increase in VE-cadherin at cell-cell borders. See Figure $6 \mathrm{~A}, \mathrm{C}$ for mean fractional intensity values, and Figure $6 \mathrm{~B}, \mathrm{D}$ for vehicle baselinesubtracted values for F-actin and VE-cadherin, respectively. $\alpha \mathrm{CT} 1$, but not $\alpha \mathrm{CT} 1-\mathrm{I}$, also prevented thrombin-induced reduction in VE-cadherin cellular distribution in the four peripheral-most cell compartments, while changes were not significant around the cell center-as indicated by the yellow-highlighted regions on the graphs shown in Figure 6. These data indicated that $\alpha \mathrm{CT} 1$ required ZO1 binding competency to protect against thrombin-induced barrier function-associated changes in F-actin and VE-cadherin.

A
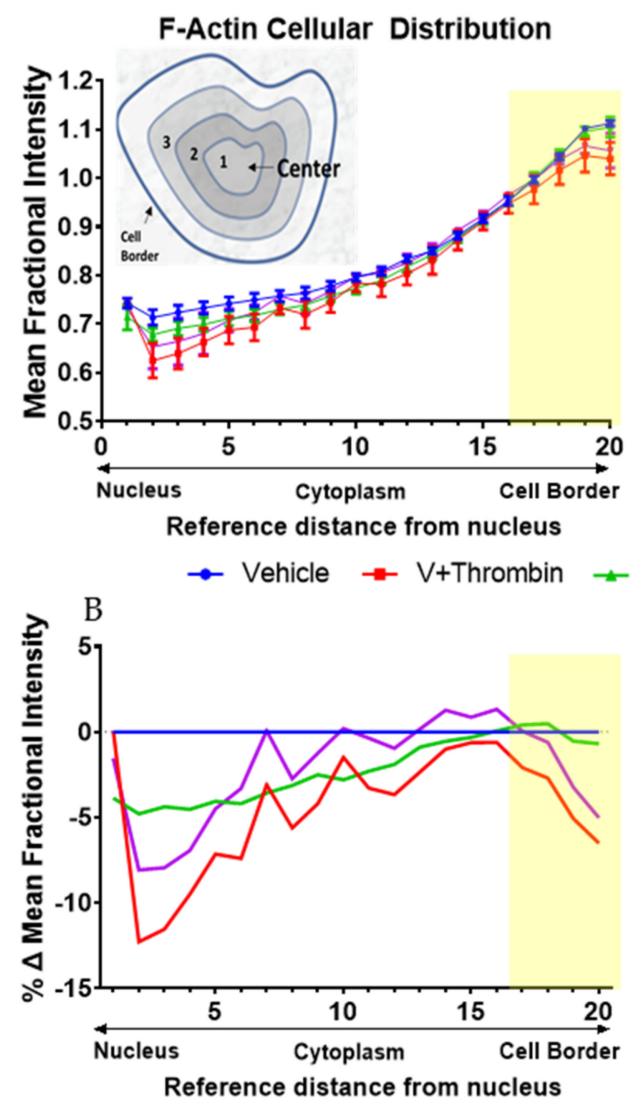

$\mathrm{C}$

VE-cadherin Cellular Distribution

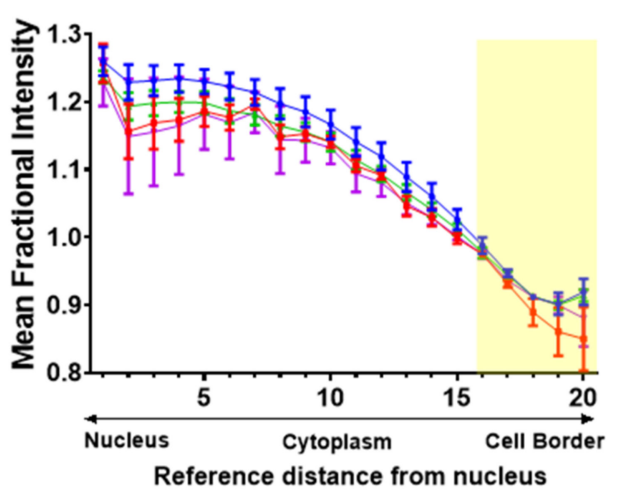

aCT1+ Thrombin * aCT1-1+ Thrombin

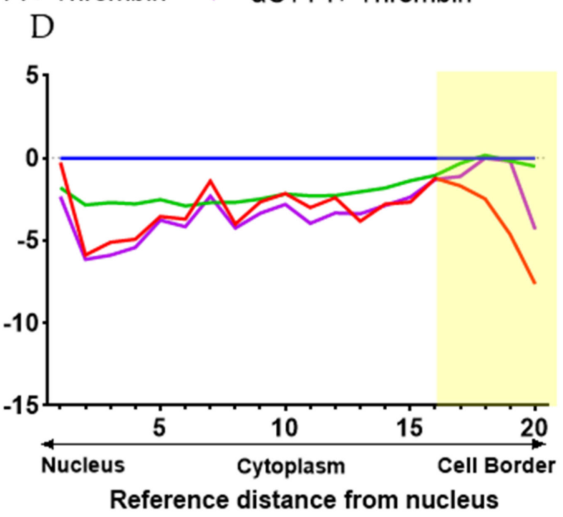

Figure 6. Quantification of $\alpha \mathrm{CT} 1$ inhibition of thrombin-induced shift in endothelial F-actin and VE-cadherin distribution in HMEC-1 cells. $(\mathbf{A}, \mathbf{C})$ The radial distributions of F-actin (top left) and VEcadherin (top right) were measured as the mean fractional intensity at a given cell radius, calculated as fraction of total intensity normalized by fraction of pixels at a given radius. Cell diagram of regions 1-20 indicated in top left figure. (B,D) F-actin (bottom left) and VE-cadherin (bottom right), vehiclesubtracted values calculated as percentage difference from vehicle 100\% (Value-Vehicle)/Vehicle). $N=3$. Yellow highlighted bar indicates where $\alpha \mathrm{CT} 1+\mathrm{T}$, but not $\alpha \mathrm{CT} 1-\mathrm{I}+\mathrm{T}$ is significant compared to thrombin alone.

3.4. $\alpha$ CT1 Requires ZO1 Binding Competency to Modulate the Distribution of F-Actin, ZO1 and Cx43 in Cultured Endothelial Cells

To further validate our observations on HMEC-1 cells, another endothelial cell line, Human Dermal Microvascular Endothelial cells (HDMECs), was grown to confluence on collagen-coated Transwell filters. HDMECs were used for purposes of improved imaging and quantification of peptide treatment-associated phenomena due to the well-defined cell-cell borders and more uniformly arrayed junctional structures found in this endothelial cell line. Previous reports have indicated that $\alpha \mathrm{CT} 1$ targets TJ protein, ZO1, to increase 
gap junctional Cx43 levels at the cell border in Hela cells, and that gap junctional Cx43 provides points of close cell-cell contact $[40,41]$. Therefore, in this set of experiments, cells were stained for F-actin, ZO1, and Cx43 (Figure 7). As in HMEC-1s, untreated vehicle control HDMECs exhibited thin, clearly delineated bands of cortical F-actin marking the boundaries of the cell, while thrombin treatment attenuated this sharp F-actin border, inducing the formation of densely packed stress fibers stretching across the cell, including the cell center. Additionally, similar to the pattern observed in HMEC-1 cells, $\alpha \mathrm{CT} 1$, but much less so $\alpha$ CT1-I, blocked this shift in F-actin distribution in HDMECs (Figure 7, and Figure 8A,B, Supplemental Table S2), with a marked attenuation and enhancement of cytosolic and peripheral F-actin distribution, respectively. HDMEC monolayers pretreated with the cell penetration sequence control, antennapedia (ANT), showed a near identical F-actin distribution pattern as thrombin treatment alone (Figure 8A,B).

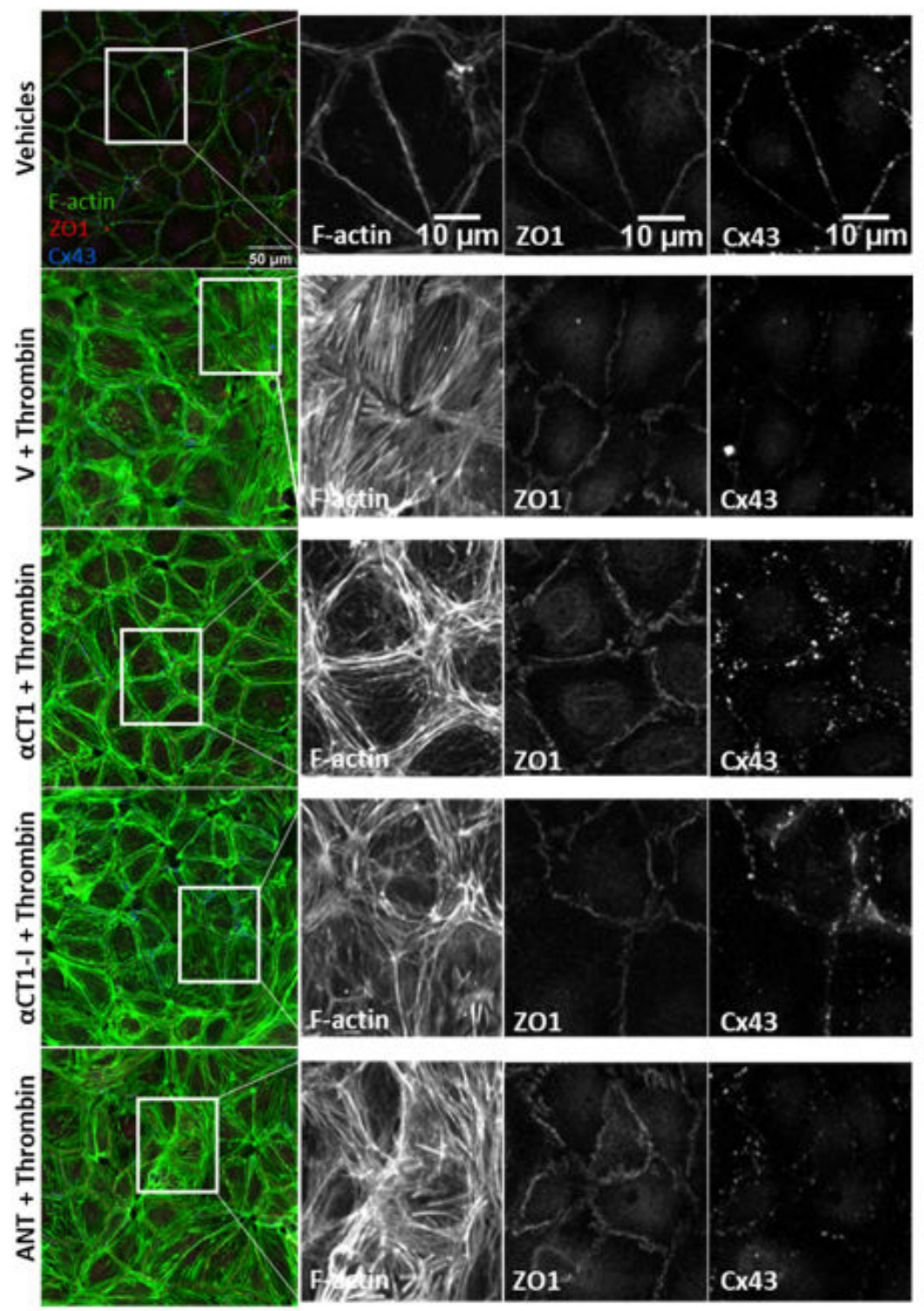

Figure 7. $\alpha \mathrm{CT} 1$ inhibits thrombin-induced shift in endothelial F-actin distribution in association with ZO1 and Cx43 remodeling in HDMEC monolayers. Representative confocal images of F-actin cytoskeleton, Cx43, and ZO1 distribution in $100 \mu \mathrm{M}$ peptide-treated, Transwell filter-grown HDMECs, fixed $10 \mathrm{~min}$ after thrombin addition to the media. Black and white zoomed images show treatmentinduced changes in more detail at the level of cell-cell contacts. 
A

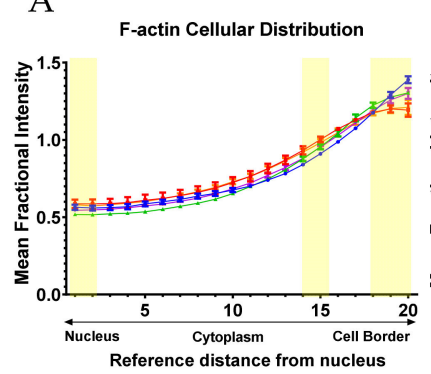

C
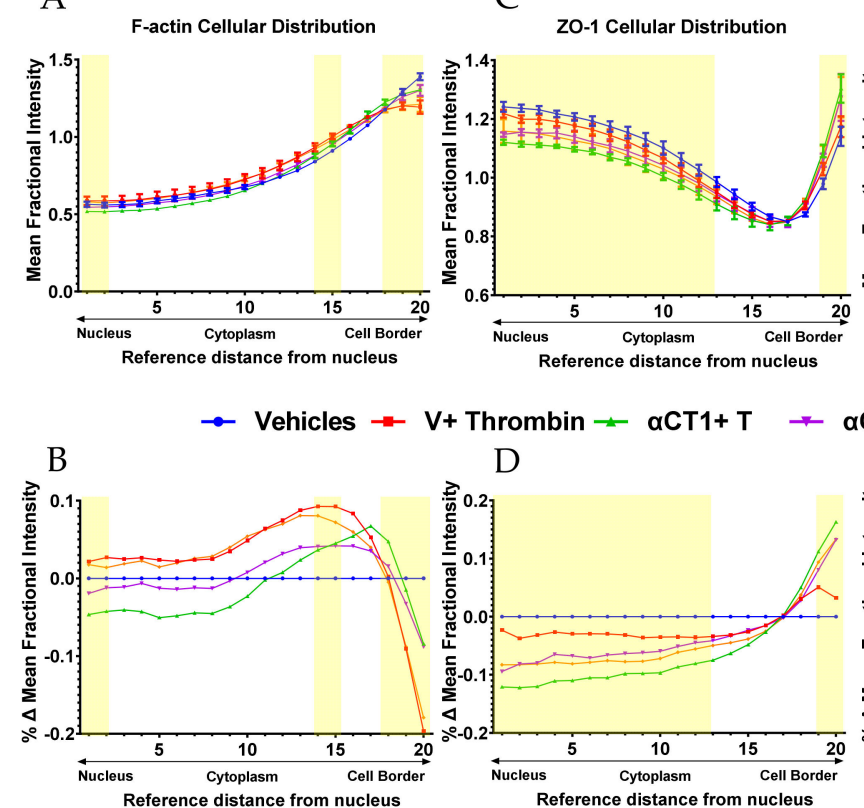

E

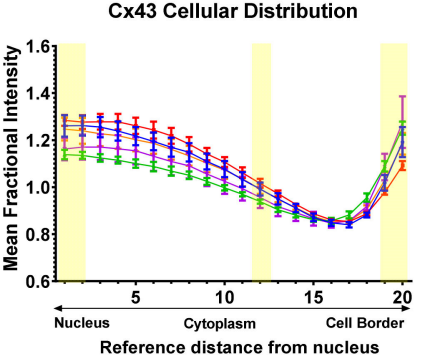

$\alpha \mathrm{CT} 1-\mathrm{I}+\mathrm{T} \rightarrow \mathrm{ANT}+\mathrm{T}$

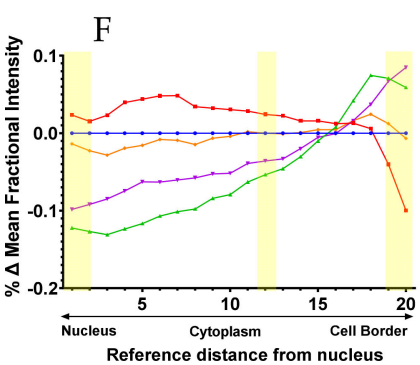

Figure 8. Quantification of $\alpha \mathrm{CT} 1$ inhibition of thrombin-induced shift in endothelial F-actin distribution in association with ZO1 and Cx43 remodeling in HDMECs. $(\mathbf{A}, \mathbf{C}, \mathbf{E})$ The radial distributions of F-actin (top left) and ZO1 (top middle) and Cx43 (top right)) were measured as the mean fractional intensity at a given cell radius, calculated as fraction of total intensity normalized by fraction of pixels at a given radius. Cell diagram of regions 1-20 indicated in top left figure. (B,D,F) F-actin (bottom left) and ZO1 (bottom middle) and Cx43 (bottom right), vehicle-subtracted values calculated as percentage difference from vehicle $100 \%$ (Value-Vehicle)/Vehicle). $N=3$. Yellow highlighted bar indicates where $\alpha \mathrm{CT} 1+\mathrm{T}$, but not $\alpha \mathrm{CT} 1-\mathrm{I}+\mathrm{T}$ or $\mathrm{ANT}+\mathrm{T}$ is significant compared to thrombin alone.

Changes in the distribution of $\mathrm{Cx} 43$ and ZO1 induced by thrombin alone did not reach statistical significance at any sub-region within HDMECs (Figure 8C-F, Supplemental Table S2). However, the effects of $\alpha \mathrm{CT} 1$ on $\mathrm{Cx} 43$ and ZO1 in combination with thrombin were significant, with marked discrimination from the effects of the $\mathrm{ZO} 1$ binding-incompetent control, $\alpha \mathrm{CT} 1-\mathrm{I}$, and the cell penetration sequence control, ANT. Consistent with previous reports on peptide-induced changes in Cx43 distribution at cell-cell contacts [32,41], $\alpha \mathrm{CT} 1$, but not $\alpha \mathrm{CT} 1-\mathrm{I}$, produced a significant increase in the proportion of Cx43 at cell-cell borders, while both peptides reduced the proportion of signal located in nuclear and cytoplasmic regions (Figure 8E, Supplemental Table S2). While at first glance, it may appear that $\alpha \mathrm{CT} 1-\mathrm{I}$, in addition to $\alpha \mathrm{CT} 1$ exhibits an increase in Cx43 at cell-cell borders, $\alpha \mathrm{CT} 1-\mathrm{I}$ showed much more variability in its response than did $\alpha \mathrm{CT} 1$ (see standard errors bars for $\alpha \mathrm{CT} 1-\mathrm{I}$ (purple) in Figure $8 \mathrm{E}$ and thus failed to reach statistical significance compared to thrombin treatment alone. Similar changes in ZO1 signal across the different cellular sub-regions were seen with $\alpha \mathrm{CT} 1$, but not $\alpha \mathrm{CT} 1$-I or ANT (Figure 8C,D, Supplemental Table S2). 95\% confidence intervals were calculated for each treatment mean at each sub-region for actin, ZO1, and Cx43 and details of statistically significant differences for these proteins between the treatment conditions compared to thrombin alone are summarized in Figure 8 and Supplemental Table S2. The yellow bars in Figure 8 indicate cell regions in which effects of $\alpha \mathrm{CT} 1$ on the junctional protein distributions are discriminated from $\alpha \mathrm{CT} 1-\mathrm{I}$ with respect to thrombin alone $(p<0.05)$. In summary, it was observed that the ZO1 binding-competent Cx43 CT peptide reduced induction of stress fibers and junctional remodeling in response to thrombin, maintaining actin in more homeostatic-like cortical distributions in the two endothelial cell lines studied. 


\section{5. $\alpha$ CT1 Requires ZO1 Binding Competency to Exert Changes in Distribution of Cell Orientations}

An F-actin cytoskeleton-related phenomenon that has been recently linked to barrier function regulation is cellular orientation or handedness [42]. We assessed cellular orientation on HDMEC monolayers treated with $\alpha \mathrm{CT} 1$, as compared to thrombin and peptide controls, and noted that distribution of cell orientations showed significant correlation to the different patterns of actin remodeling seen in our experimental model (Figure 9). Skewness measurements of cell orientation indicated that thrombin shifts the distribution of cell orientation from one side of a normal distribution to the other. That is, under vehicle conditions, the majority of cell orientations took on "negative" angles with respect to an arbitrary $X=0^{\circ}$ reference axis, while thrombin stimulation "flipped" the cells to take on positive angles. $\alpha \mathrm{CT} 1$ pronouncedly reduced the skewness measure to near zero, indicating a near complete attenuation of cell-orientation bias. A Kolmogorov-Smirnov (KS) test on cell orientation data was performed to further confirm the significance of these findings.
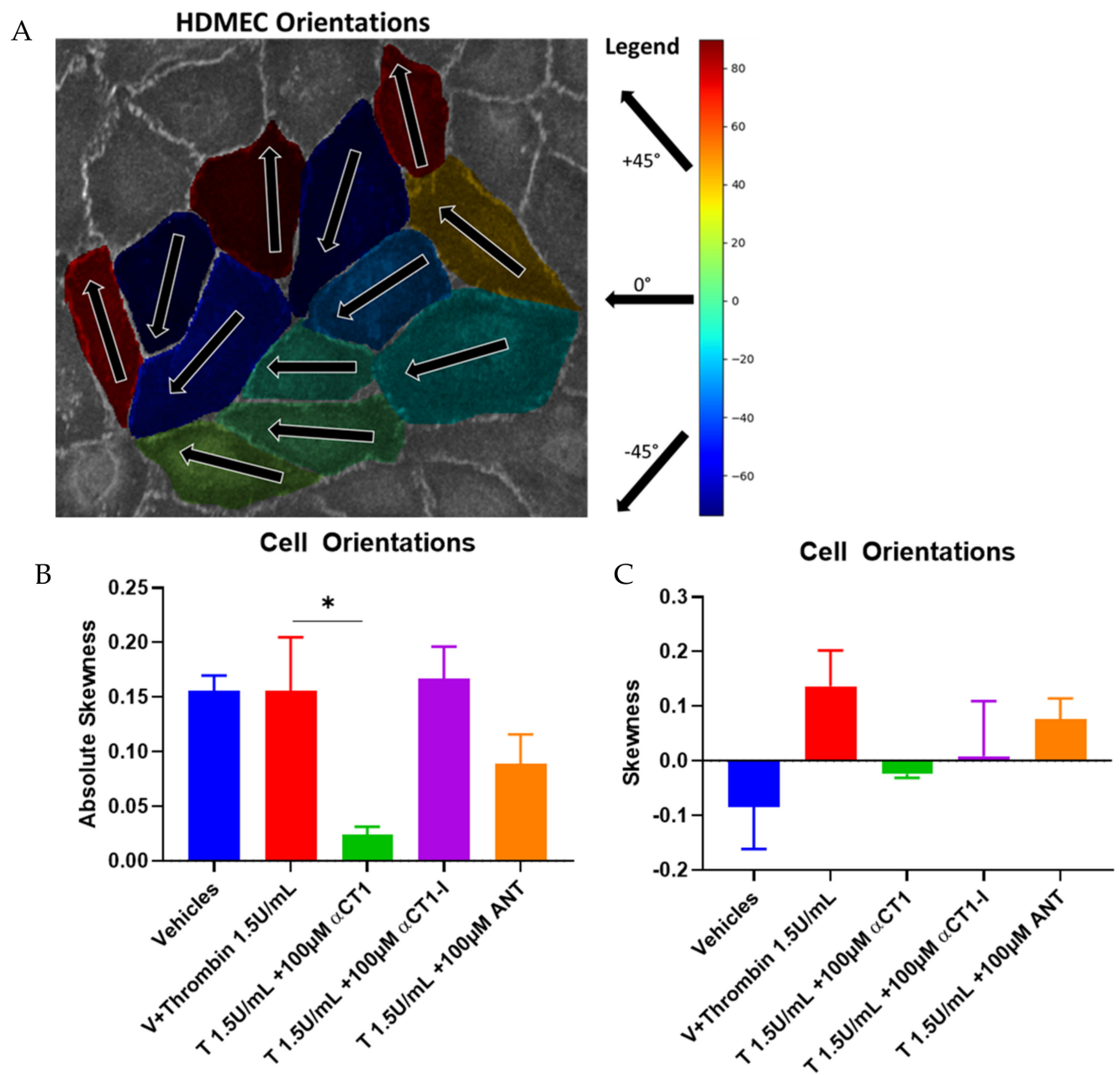

Figure 9. $\alpha \mathrm{CT} 1$ alters distribution of cell orientations in HDMEC monolayers. (A) Representative diagram of cell angle designation across a HDMEC monolayer. (B) Absolute skewness measurements, calculated as the absolute value of $\mathrm{g} 1=$ the average value of $\mathrm{z}^{3}$, where $\mathrm{z}$ is the familiar $\mathrm{z}$-score, $\mathrm{z}=(x-\bar{x}) / \sigma$, where $\mathrm{x}$ is the individual cell angle with respect to $0^{\circ}$ angle reference axis. (C) Raw skewness values calculated as g1 above, no absolute value calculated, ${ }^{*} p<0.05$ vs. Thrombin; $N=3$.

\section{6. $\alpha$ CT1 Reduces Vascular Leak in Langendorff-Perfused Mouse Hearts}

As mentioned earlier, a cardiovascular protective effect of $\alpha \mathrm{CT} 1$ was hypothesized to in part result from the peptide's targeting to the coronary vasculature within the heart [33]. Thus, to determine if the in vitro endothelial barrier protection by $\alpha \mathrm{CT} 1 \mathrm{ap}-$ plied to an ex vivo setting, vascular leakage within peptide-treated mouse hearts was 
assessed. Langendorff-perfused mouse hearts were perfused for 20 min with Tyrode's solution with or without $\alpha \mathrm{CT} 1(100 \mu \mathrm{M})$, followed by 40 min with thrombin $(1.5 \mathrm{U} / \mathrm{mL})$. The permeability tracer FITC-dextran $(10 \mathrm{mg} / \mathrm{mL})$, a similar tracer used previously in the Transwell permeability assay (Figure 3), was added to the final $10 \mathrm{~mL}$ of perfusate. Overall, as assessed by quantitative confocal microscopy of cryosections from the hearts, thrombin significantly increased FITC extravasation relative to control (by $\sim 88 \%$ ). $\alpha \mathrm{CT} 1$ treatment markedly decreased FITC extravasation compared to thrombin alone $(p<0.05$ vs. thrombin), nearly restoring it to vehicle control levels (Figure 10).

A

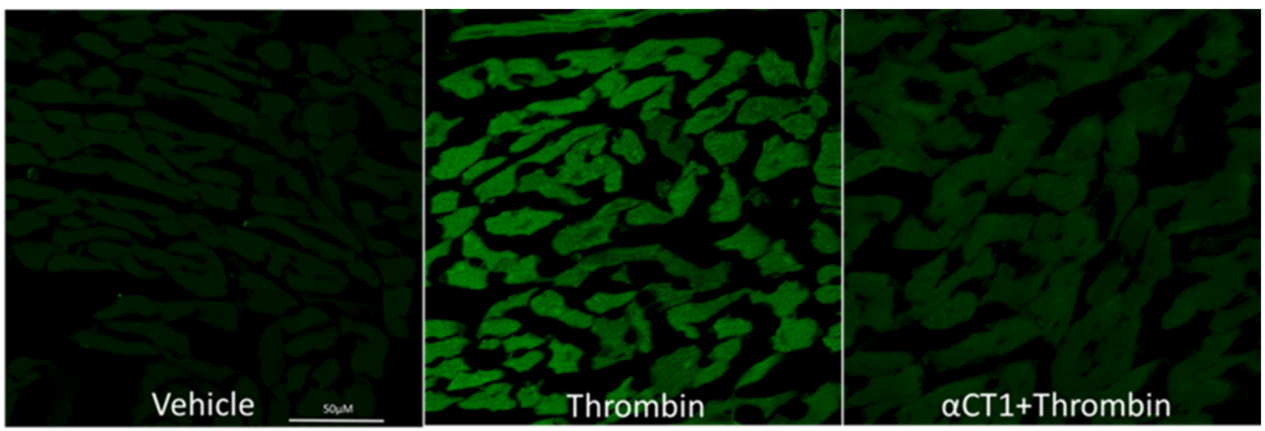

\section{B}
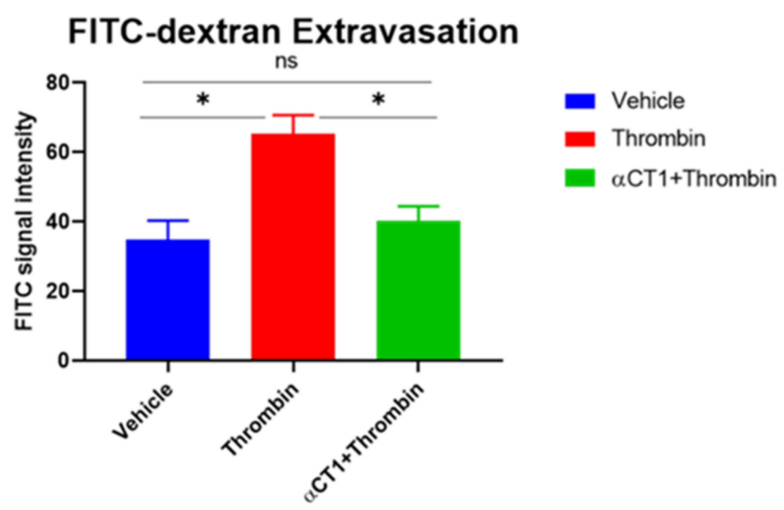

Figure 10. $\alpha \mathrm{CT} 1$ inhibits thrombin-intravascular leak in Langendorff-perfused mouse hearts. (A) Representative confocal images of FITC-dextran extravasation within Langendorff-perfused mouse hearts. (B) Quantification of FITC-dextran signal within mouse hearts perfused 40 min with thrombin $(1.5 \mathrm{U} / \mathrm{mL})$ with or without $20 \mathrm{~min} \alpha \mathrm{CT} 1(100 \mu \mathrm{M})$ pretreatment. SE bars, ${ }^{*} p<0.05$. ns $=$ not significant.

\section{Discussion}

In this study, we investigated the effects of Cx43 CT mimetic peptide $\alpha \mathrm{CT} 1$ on transendothelial permeability and junctional and cytoskeletal proteins that determine this function. We found that pretreatment with $\alpha \mathrm{CT} 1$ protects vascular barrier function from thrombin-induced disruption in ex vivo (Langendorff-perfused mouse heart) and in vitro (ECIS and Transwell permeability) models. Barrier protection in vitro by $\alpha$ CT1 occurred in association with localization of the peptide with $\mathrm{ZO} 1$ at cell-to-cell borders, specific effects on cell orientation and changes in patterns of F-actin, VE-cadherin, Cx43, and ZO1 remodeling, particularly at the periphery of cells. Importantly, a ZO1 binding-incompetent variant of $\alpha \mathrm{CT} 1, \alpha \mathrm{CT} 1-\mathrm{I}$, showed no propensity to associate with ZO1 at the cell periphery and also demonstrated no facility for protecting barrier function, suggesting that ZO1 binding competency is required for Cx43 CT mimetic peptides to affect the vascular permeability parameters assessed.

The findings we present herein are consistent with previous studies indicating a protective role of $\mathrm{Cx} 43 \mathrm{CT}$ in channel-independent modulation of barrier function. Mice deficient in the Cx43 CT die as a result of epithelial barrier dysfunction, despite maintaining normal GJIC [43]. Obert and colleagues (2017) showed that the Cx43 CT mimetic, $\alpha$ CT1 
prevented breakdown of TJ-based barrier function via a channel-independent mechanism, in Cx43-expressing epithelial cell lines derived from the retinal pigment layer [31]. Three novel insights from the present study are that: (1) in addition to protecting epithelial cell barriers, $\alpha \mathrm{CT} 1$ is protective of barrier function in endothelial cells; (2) the terminal isoleucine of $\alpha \mathrm{CT} 1$, and thus maintenance of the peptide's high-affinity interaction with the PDZ2 domain of ZO1, appears to be required for barrier protective properties in the models studied; and (3) the inhibitory effect of $\alpha \mathrm{CT} 1$ on actin remodeling in response to a stressor such as thrombin appears to be central to the activity of the peptide in barrier function protection.

A major finding of this study is that $\alpha \mathrm{CT} 1$ inhibits thrombin-induced attenuation of cortical actin and F-actin stress fiber formation. In intact endothelial barriers, cortical actin, in association with junctional complexes, exerts outward directed tension between cells, in dynamic balance with opposing inward contractile forces within cells. The actin stress fiber phenotype induced by thrombin shifts the balance of forces within and between cells, resulting in a disruption of cell contacts, formation of extracellular gaps and breakdown of barrier properties $([3,11,36]$ — see also Figure 11). In addition to thrombin, numerous other chemical and physical stressors, including histamine, lipopolysaccharide, endotoxin, Tissue Necrosis Factor (TNF), and shear stress, cause similar shifts in the balance of intra- and intercellular forces, together with loss of barrier patency via the same actinomyosin-based mechanism. For example, Mehta and colleagues (2002) showed that pretreating Human Pulmonary Artery Endothelial Cells (HPAEC) with latrunculin-A (Lat-A), a toxin known to prevent F-actin assembly, inhibited thrombin-induced endothelial cell retraction and decreased loss of transepithelial electrical resistance (TEER) [44] Pertinent to the current study, a report by Chen and colleagues (2015) found that $\alpha \mathrm{CT} 1$ produced derangement of cytoskeletal fibers when applied to brain endothelial cells, including formation of cytoplasmic actin-rich node-like structures [37]. Interestingly, the authors also reported that these results could be recapitulated by over- expressing a PDZ2 domain-deleted ZO1 mutant, suggesting that the Cx43-binding domain of ZO1 targeted by $\alpha \mathrm{CT} 1$ was necessary for the observed effects on actin cytoskeleton organization.

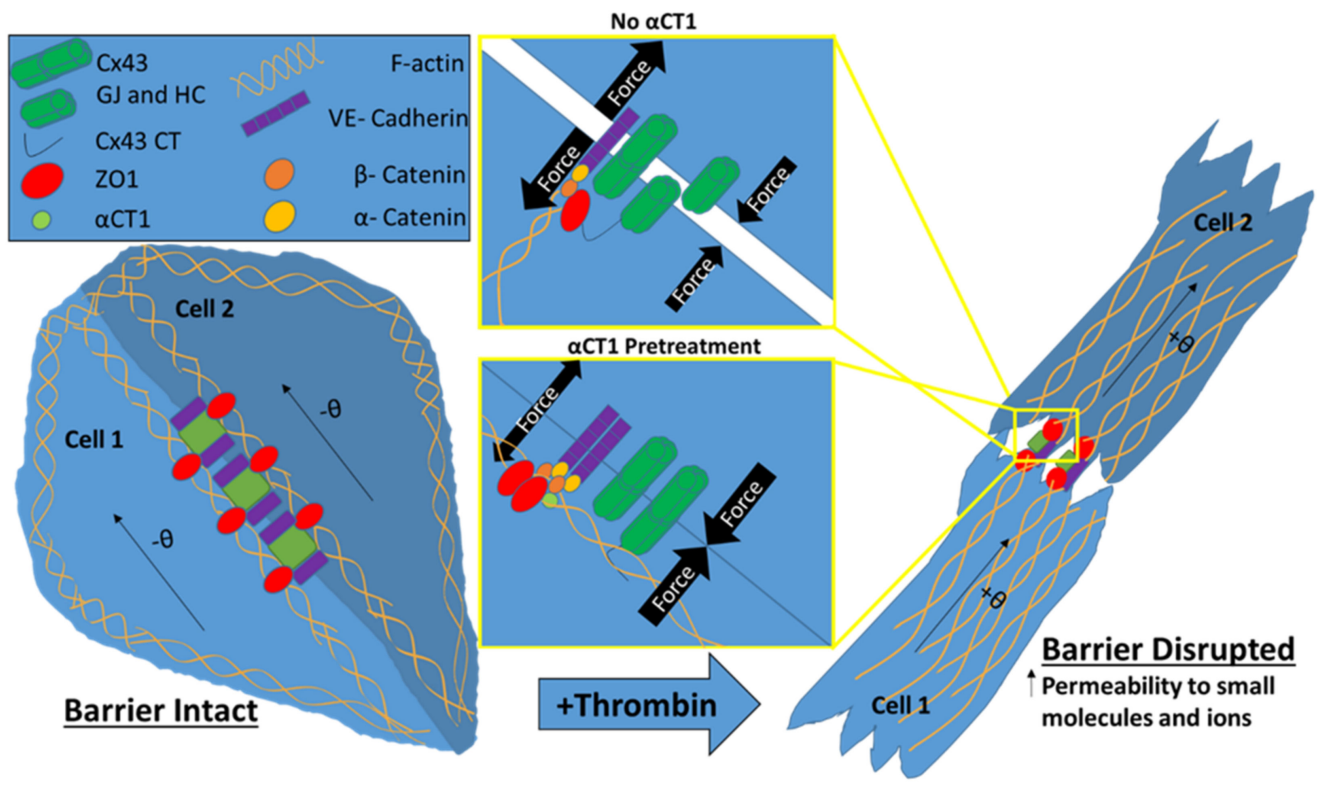

Figure 11. Simplified model of $\alpha \mathrm{CT} 1$ effects on endothelial cells in monolayers under thrombin stimulation. Thrombin stimulation of endothelial cells produces a redistribution of F-actin from peripherally located cortical actin to stress fibers that cut across the cytoplasm. These stress fibers terminate onto VE-cadherin containing adherens junctions at the cytoplasmic plaque of the membrane, and in their contractile state, and are thought to exert barrier-destabilizing pulling forces at the cell membranes of opposing cells [45]. This accompanies a reduction and remodeling of adherens junctions, 
intercellular gap formation and increased permeability to small molecules and ions. In correlation with these changes, thrombin flips the F-actin controlled orientation of cells in the monolayer to take on angles opposite to those observed in homeostatic conditions in which the barrier is intact [42]. $\alpha \mathrm{CT} 1$ pretreatment of endothelial monolayers appears to inhibit these thrombin-induced changes in a ZO1-interaction-dependent manner, reducing stress fiber formation and maintaining actin in more cortical distributions. $\alpha \mathrm{CT} 1$ treatment is also associated with increased $\mathrm{Cx} 43$ gap junctional contacts, maintenance of VE-cadherin-containing adherens junctions and ZO1-containing tight junctions at cell borders. We hypothesize that uncoupling of ZO1 from anchorage at key membrane-associated partner proteins (e.g., Cx43, $\alpha$-catenin) via ligand binding to its PDZ2 domain (e.g., by $\alpha \mathrm{CT} 1$ ), may offset the perpendicular alignment of F-actin fibers. This in turn may reduce the ability of stress fibers aligned in this manner to exert centripetal force onto the cytoplasmic face of adherens junctions, reducing extracellular gap formation, stabilizing the endothelial barrier and maintaining heterogeneous patterns of cell orientation in response to stressors such as thrombin.

We have previously demonstrated that pretreatment with either $\alpha \mathrm{CT} 1$ or $\alpha \mathrm{CT} 1-\mathrm{I}$ can reduce the severity of myocardial ischemia-reperfusion (IR) injury [33]. These results in myocardium stand in contrast to the apparent mechanism of the selective vascular endothelial barrier protective effect of $\alpha \mathrm{CT} 1$ characterized herein. The shared myocardial protective effect of $\alpha \mathrm{CT} 1$ and $\alpha \mathrm{CT} 1-\mathrm{I}$ occurs independent of ZO1 interaction, and is correlated with negatively charged sequences common to both peptides, which mediate binding to the $\mathrm{H} 2$ domain of Cx43 [33]. The severity of heart IR injuries is thought in part to be determined by levels of activation of myocardial Cx43 hemichannels $[46,47]$ and we have previously proposed that reductions in channel activity associated with targeting the $\mathrm{Cx} 43 \mathrm{H} 2$ domain (a short $\alpha$-helical sequence within the Cx43 CT) [41] could account for the cardioprotective effects elicited by $\alpha \mathrm{CT} 1$ and $\alpha \mathrm{CT} 1-\mathrm{I}$. [33]. By contrast, increased trans-epithelial permeability in endothelial monolayers subject to a thrombin insult, as studied herein, seems to be primarily mediated via effects on actin organization and shifts in forces exerted on intercellular contacts downstream of this remodeling of the cytoskeleton [36,48] Actin's propensity to interact with ZO1, or membrane bound actin-binding ZO1 partners such as cytoplasmic components of adherens junctions (e.g., $\alpha$-catenin [49]), and its capacity to form and align stress fibers, appears to be sensitive to a $\alpha$ CT1-induced modulation of ZO1 following exposure of cells to thrombin. That $\alpha \mathrm{CT} 1$ treatment resulted in altered patterns of actin cytoskeleton remodeling, and in particular to that of cortical actin at the cell periphery, is also consistent with thrombin's well-established mode of action on vascular permeability [50].

Our results indicate that $\alpha \mathrm{CT} 1$ inhibits a thrombin-induced reversal of cell orientation, pronouncedly attenuating cell orientation bias in a ZO1 interaction-associated manner, while enhancing ZO1 localization at cell boundaries. Cell orientation distribution has been linked to actin-mediated ZO1-associated barrier integrity in a pioneering study carried out by Fan and colleagues [42]. These authors determined that endothelial barrier disruption triggered by a PKC activator indolactam V (IndoV), correlated to reduced ZO1 expression and actin-dependent reversal of cell orientation. Thrombin and IndoV share the mechanistic mediation by the same PKC (i.e., PKC $\alpha$ ) causally linked to the reversal of cell orientation in the study performed by Fan and colleagues. In endothelial cells used in the current study, thrombin stimulation appeared to impose uniformity in the angle of actin stress fibers cutting across cells. Cell orientation in this study, was measured by the angle that the cells take on across their long axis, which is the same axis along which stress fibers align in parallel within the cell and often within neighboring cells. Skewness measurements of cell orientation undertaken in our study indicate that thrombin shifts the distribution of cell orientation from one side of a normal distribution to the other. While the analysis in the present study was not carried using a well-defined reference axis based on the tangential direction of a micro-patterned circular array as in the study by Fan and co-workers [42], our skewness results are consistent with their observations. Ongoing studies may usefully focus on if and how Cx43 and Cx43/ZO1 interactions may operate 
in this context, potentially contributing to the handedness of actin cytoskeletal and cell orientation responses.

In the current study, $\alpha \mathrm{CT} 1$ maintained F-actin at the cell periphery under thrombin stimulation, while at the same time augmenting the border localization of $\mathrm{Cx} 43, \mathrm{ZO} 1$, and VE-cadherin. It is well established that stabilization of barrier function is often marked by restoration of AJ and TJ proteins to cell-cell borders [14,51]. Furthermore, multiple studies have demonstrated cell-cell adhesive roles for Cx43 GJ [40,52,53], and the upregulation of GJ Cx43 has been shown to promote a stabilization of cortical actin $[18,54,55]$. Under normal conditions, cortical actin promotes the stability of cell-cell interactions by tethering these junctional structures (e.g., GJ, TJ, and AJ) with other intracellular components [10-12]. Taken together, our data suggest that $\alpha \mathrm{CT} 1$ protects barrier function first and foremost by inhibiting a shift in F-actin away from cell-to-cell contacts, thereby stabilizing transcellular interacting proteins, VE-cadherin and Cx43, and the TJ-scaffolding protein ZO1. Figure 11 provides a model of how $\alpha \mathrm{CT} 1$ pretreatment could enhance outward directed tension and minimize inward directed pulling forces via modulation of actin and junctional protein distribution, with downstream effects on endothelial gap formation and barrier permeability.

Further insight into $\alpha \mathrm{CT} 1^{\prime}$ s mechanism can be gained from the literature on the role of sphingolipid, Sphingosine-1-phosphate (S1P) in barrier modulation. A report by Want et al. using atomic force microscopy showed that thrombin caused a decrease in cortical actin, concomitant with a drop in cell stiffness at the cell border, while S1P had opposite effects [56]. Moreover, Lee and colleagues [57] demonstrated that in association with barrier function stabilization as measured by ECIS, S1P stimulation caused a redistribution of ZO1 and Claudin- 5 to cell-cell contacts, and enhanced border colocalizations of ZO1/ cortactin and ZO1/ $\alpha$-catenin in Human Umbilical Vein Endothelial Cells (HUVECs). While no known direct interaction between $\mathrm{S} 1 \mathrm{P}$ and $\mathrm{ZO} 1$ has been identified to date, we speculate that the CT of Cx43 (either endogenous or exogenously applied in the form of $\alpha \mathrm{CT} 1$ ) and S1P may share a similar mode of action in modulating ZO1/actin-mediated effects on endothelial barrier function.

In addition to utility of $\alpha \mathrm{CT} 1$ as a tool for addressing basic research questions about the potential role of $\mathrm{Cx} 43 \mathrm{CT}$ in barrier function, the therapeutic potential of this peptide in the treatment of vascular edema could be considerable. $\alpha \mathrm{CT} 1$ has undergone clinical testing in humans for a number of skin-related disease indications, including in healing of chronic wounds, where swelling and edema, and thus disrupted barrier function, are well characterized aspects of pathology [58-62]. In the present study, $\alpha \mathrm{CT} 1$ pronouncedly attenuated vascular leak in Langendorff-perfused mouse hearts. For a large set of disorders (e.g., sepsis, ischemia-reperfusion (IR) injury, major trauma, organ transplantation) and tissue types, organ dysfunction and patient outcomes associate with microvascular dysfunction and edema [5]. In other studies, we have also linked edema, such as that occurs following injury to the heart, to increased propensity to develop deadly arrhythmias $[63,64]$. Given the findings from the present study, $\alpha$ CT1 might be considered a potential vascular-targeting, anti-edema treatment strategy for cardiovascular injury and other diseases in which edematous accumulation is detrimental. Thus, future work might investigate whether the ability of $\alpha \mathrm{CT} 1$ to inhibit of vascular leakage within the heart extends to vascular barrier protection in other tissues/organs.

Supplementary Materials: The following are available online at https: / www.mdpi.com/article / 10.3390/biom11081192/s1, Figure S1: $\alpha$ CT1 augments barrier function recovery in Cx43-deficient MDCK cells. Table S1: Peptide treatments with significant effects compared to thrombin treatment alone in HMEC-1. Table S2: Peptide treatments with significant effects compared to thrombin treatment alone in HDMECs.

Author Contributions: Conceptualization and design, experimental investigation and writing, R.E.S.; conceptualization and design, and writing - review and editing, R.G.G.; experimental contributions, L.M. and R.V. All authors have read and agreed to the published version of the manuscript. 
Funding: The work in the lab of R.G.G. is supported by the National Heart, Lung, and Blood Institute (NHLBI) of the National Institute of Health (NIH) under the F31 Grant HL145982 for R.E.S., as well as R01HL056728-19 and R01HL14155-04 for R.G.G.

Institutional Review Board Statement: Not applicable.

Informed Consent Statement: Not applicable.

Data Availability Statement: Data are available upon request.

Acknowledgments: We would like to thank Jane Jourdan for her technical assistance with some of the experiments conducted in this manuscript. Ian Crandell (PhD) and Jennifer West (MS) are thanked for their expert guidance on a few of the statistics components of the manuscript.

Conflicts of Interest: R.G.G. is a non-remunerated member of the Scientific Advisory Board of FirstString Research, which licensed alpha-carboxyl terminus 1 peptide. R.G.G. has a small ownership interest in FirstString Research Inc. ( $<1 \%$ of company stock). R.E.S. has no disclosures to report.

\section{References}

1. Zihni, C.; Mills, C.; Matter, K.; Balda, M. Tight junctions: From simple barriers to multifunctional molecular gates. Nat. Rev. Mol. Cell Biol. 2016, 17, 564-580. [CrossRef]

2. Higashi, T.; Miller, A.L. Tricellular junctions: How to build junctions at the TRICkiest points of epithelial cells. Mol. Biol. Cell 2017, 28, 2023-2034. [CrossRef]

3. Escribano, J.; Chen, M.B.; Moeendarbary, E.; Cao, X.; Shenoy, V.; Garcia-Aznar, J.M.; Kamm, R.D.; Spill, F. Balance of me-chanical forces drives endothelial gap formation and may facilitate cancer and immune-cell extravasation. PLoS Comput. Biol. 2019, 15, e1006395. [CrossRef]

4. Herrero, R.; Sanchez, G.; Lorente, J.A. New insights into the mechanisms of pulmonary edema in acute lung injury. Ann. Transl. Med. 2018, 6, 32. [CrossRef] [PubMed]

5. Heusch, G. The Coronary Circulation as a Target of Cardioprotection. Circ. Res. 2016, 118, 1643-1658. [CrossRef] [PubMed]

6. Heusch, G. Protection of the human coronary circulation by remote ischemic conditioning. Int. J. Cardiol. 2018, 252, 35-36. [CrossRef] [PubMed]

7. Simmons, S.; Erfinanda, L.; Bartz, C.; Kuebler, W.M. Novel mechanisms regulating endothelial barrier function in the pulmonary microcirculation. J. Physiol. 2018, 597, 997-1021. [CrossRef] [PubMed]

8. Soon, A.S.C.; Chua, J.W.; Becker, D.L. Connexins in endothelial barrier function-Novel therapeutic targets countering vascular hyperpermeability. Thromb. Haemost. 2016, 116, 852-867. [CrossRef] [PubMed]

9. Aghajanian, A.; Wittchen, E.S.; Allingham, M.J.; Garrett, T.A.; Burridge, K. Endothelial cell junctions and the regulation of vascular permeability and leukocyte transmigration. J. Thromb. Haemost. 2008, 6, 1453-1460. [CrossRef] [PubMed]

10. Komarova, Y.; Malik, A.B. Regulation of Endothelial Permeability via Paracellular and Transcellular Transport Pathways. Annu. Rev. Physiol. 2010, 72, 463-493. [CrossRef]

11. Belvitch, P.; Htwe, Y.M.; Brown, M.E.; Dudek, S. Cortical Actin Dynamics in Endothelial Permeability. Basement Membr. 2018, 82, 141-195. [CrossRef]

12. Giepmans, B. Gap junctions and connexin-interacting proteins. Cardiovasc. Res. 2004, 62, 233-245. [CrossRef]

13. Derangeon, M.; Spray, D.; Bourmeyster, N.; Sarrouilhe, D.; Hervé, J.-C. Reciprocal influence of connexins and apical junction proteins on their expressions and functions. BBA Biomembr. 2009, 1788, 768-778. [CrossRef] [PubMed]

14. Radeva, M.Y.; Waschke, J.; Radeva, M.Y.; Waschke, J. Mind the gap: Mechanisms regulating the endothelial barrier. Acta Physiol. 2018, 222, e12860. [CrossRef]

15. Hervé, J.-C.; Bourmeyster, N.; Sarrouilhe, D.; Duffy, H.S. Gap junctional complexes: From partners to functions. Prog. Biophys. Mol. Biol. 2007, 94, 29-65. [CrossRef] [PubMed]

16. Garcia, J.G. Concepts in microvascular endothelial barrier regulation in health and disease. Microvasc. Res. 2009, 77, 1-3. [CrossRef]

17. Strauss, R.E.; Gourdie, R.G. Cx43 and the Actin Cytoskeleton: Novel Roles and Implications for Cell-Cell Junction-Based Barrier Function Regulation. Biomolecules 2020, 10, 1656. [CrossRef] [PubMed]

18. Francis, R.; Xu, X.; Park, H.; Wei, C.-J.; Chang, S.; Chatterjee, B.; Lo, C. Connexin43 Modulates Cell Polarity and Directional Cell Migration by Regulating Microtubule Dynamics. PLoS ONE 2011, 6, e26379. [CrossRef]

19. Leithe, E.; Mesnil, M.; Aasen, T. The connexin 43 C-terminus: A tail of many tales. BBA Biomembr. 2018, 1860, 48-64. [CrossRef]

20. Kameritsch, P.; Pogoda, K.; Pohl, U. Channel-independent influence of connexin 43 on cell migration. BBA Biomembr. 2012, 1818, 1993-2001. [CrossRef]

21. Olk, S.; Zoidl, G.; Dermietzel, R. Connexins, cell motility, and the cytoskeleton. Cell Motil Cytoskeleton. 2009, 66, $1000-1016$. [CrossRef]

22. Matsuuchi, L.; Naus, C.C. Gap junction proteins on the move: Connexins, the cytoskeleton and migration. BBA Biomembr. 2013, 1828, 94-108. [CrossRef] 
23. Sorgen, P.L.; Trease, A.J.; Spagnol, G.; Delmar, M.; Nielsen, M.S. Protein-Protein Interactions with Connexin 43: Regulation and Function. Int. J. Mol. Sci. 2018, 19, 1428. [CrossRef]

24. Sorgen, P.L.; Duffy, H.S.; Sahoo, P.; Coombs, W.; Delmar, M.; Spray, D.C. Structural Changes in the Carboxyl Terminus of the Gap Junction Protein Connexin43 Indicates Signaling between Binding Domains for c-Src and Zonula Occludens-1. J. Biol. Chem. 2004, 279, 54695-54701. [CrossRef] [PubMed]

25. Giepmans, B.; Moolenaar, W.H. The gap junction protein connexin43 interacts with the second PDZ domain of the zona occludens-1 protein. Curr. Biol. 1998, 8, 931-934. [CrossRef]

26. Laird, D.W.; Lampe, P.D. Therapeutic strategies targeting connexins. Nat. Rev. Drug Discov. 2018, 17, 905-921.

27. Giepmans, B.N.G.; Moolenaar, W.H. Pitfalls in assessing microvascular endothelial barrier function: Impedance-based devices versus the classic macromolecular tracer assay. Sci. Rep. 2016, 6, 23671.

28. Gullberg, M.; Andersson, A.-C. Visualization and quantification of protein-protein interactions in cells and tissues. Nat. Methods 2010, 7, v-vi. [CrossRef]

29. McQuin, C.; Goodman, A.; Chernyshev, V.; Kamentsky, L.; Cimini, B.A.; Karhohs, K.W.; Doan, M.; Ding, L.; Rafelski, S.M.; Thirstrup, D.; et al. CellProfiler 3.0: Next-generation image processing for biology. PLoS Biol. 2018, 16, e2005970. [CrossRef]

30. R Core Team. Core R: A Language and Environment for Statistical Computing; Version 2.6.2 (2008-02-08); R Core Team: Vienna, Austria, 2020.

31. Obert, E.; Strauss, R.; Brandon, C.; Grek, C.; Ghatnekar, G.; Gourdie, R.; Rohrer, B. Targeting the tight junction protein, zonula occludens-1, with the connexin43 mimetic peptide, $\alpha$ CT1, reduces VEGF-dependent RPE pathophysiology. J. Mol. Med. 2017, 95, 535-552. [CrossRef] [PubMed]

32. Hunter, A.W.; Barker, R.J.; Zhu, C.; Gourdie, R.G. Zonula Occludens-1 Alters Connexin43 Gap Junction Size and Organization by Influencing Channel Accretion. Mol. Bio. Cell 2005, 16, 5686-5698. [CrossRef]

33. Jiang, J.; Hoagland, D.; Palatinus, J.A.; He, H.; Iyyathurai, J.; Jourdan, L.J.; Bultynck, G.; Wang, Z.; Zhang, Z.; Schey, K.; et al. Interaction of $\alpha$ Carboxyl Terminus 1 Peptide With the Connexin 43 Carboxyl Terminus Preserves Left Ventricular Function After Ischemia-Reperfusion Injury. J. Am. Hear. Assoc. 2019, 8, e012385. [CrossRef] [PubMed]

34. Jackson, S.P.; Darbousset, R.; Schoenwaelder, S.M. Thromboinflammation: Challenges of therapeutically targeting co-agulation and other host defense mechanisms. Blood 2019, 133, 906-918. [CrossRef] [PubMed]

35. Breslin, J.W.; Zhang, X.E.; Worthylake, R.A.; Souza-Smith, F.M. Involvement of Local Lamellipodia in Endothelial Barrier Function. PLoS ONE 2015, 10, e0117970. [CrossRef]

36. Aslam, M.; Tanislav, C.; Troidl, C.; Schulz, R.; Hamm, C.; Gündüz, D. cAMP controls the restoration of endothelial barrier function after thrombin-induced hyperpermeability via Rac1 activation. Physiol. Rep. 2014, 2, e12175. [CrossRef] [PubMed]

37. Chen, C.H.; Mayo, J.N.; Gourdie, R.G.; Johnstone, S.R.; Isakson, B.E.; Bearden, S.E. The connexin 43/ZO-1 complex regulates cerebral endothelial F-actin architecture and migration. Am. J. Physiol. Cell Physiol. 2015, 309, C600-C607. [CrossRef]

38. Rabiet, M.-J.; Plantier, J.-L.; Rival, Y.; Genoux, Y.; Lampugnani, M.-G.; Dejana, E. Thrombin-Induced Increase in Endo-thelial Permeability Is Associated With Changes in Cell-to-Cell Junction Organization. Arterioscler. Thromb. Vasc. Biol. 1996, 16, 488-496. [CrossRef]

39. Doggett, T.M.; Breslin, J.W. Study of the Actin Cytoskeleton in Live Endothelial Cells Expressing GFP-Actin. J. Vis. Exp. 2011, e3187. [CrossRef]

40. Elias, L.A.B.; Wang, D.D.; Kriegstein, A.R. Gap junction adhesion is necessary for radial migration in the neocortex. Nat. Cell Biol. 2007, 448, 901-907. [CrossRef] [PubMed]

41. Rhett, J.M.; Jourdan, J.; Gourdie, R.G. Connexin 43 connexon to gap junction transition is regulated by zonula occludens-1. Mol. Biol. Cell 2011, 22, 1516-1528. [CrossRef]

42. Fan, J.; Ray, P.; Lu, Y.W.; Kaur, G.; Schwarz, J.J.; Wan, L.Q. Cell chirality regulates intercellular junctions and endothelial permeability. Sci. Adv. 2018, 4, eaat2111. [CrossRef]

43. Maass, K.; Ghanem, A.; Kim, J.-S.; Saathoff, M.; Urschel, S.; Kirfel, G.; Grümmer, R.; Kretz, M.; Lewalter, T.; Tiemann, K.; et al. Defective Epidermal Barrier in Neonatal Mice Lacking the C-Terminal Region of Connexin43. Mol. Biol. Cell 2004, 15, 4597-4608. [CrossRef]

44. Mehta, D.C.; Tiruppathi, R.; Sandoval, R.D.; Minshall, M.; Holinstat, M.; Malik, A.B. Modulatory role of focal adhesion kinase in regulating human pulmonary arterial endothelial barrier function. J. Physiol. 2002, 539, 779-789. [CrossRef] [PubMed]

45. Burridge, K.; Wittchen, E.S. The tension mounts: Stress fibers as force-generating mechanotransducers. J. Cell Biol. 2013, 200, 9-19. [CrossRef]

46. Marsh, S.R.; Williams, Z.J.; Pridham, K.J.; Gourdie, R.G. Peptidic Connexin43 Therapeutics in Cardiac Reparative Medi-cine. J. Cardiovasc. Dev. Dis. 2021, 8, 52. [CrossRef]

47. Schulz, R.; Görge, P.M.; Görbe, A.; Ferdinandy, P.; Lampe, P.D.; Leybaert, L. Connexin 43 is an emerging therapeutic target in ischemia/reperfusion injury, cardioprotection and neuroprotection. Pharmacol. Ther. 2015, 153, 90-106. [CrossRef] [PubMed]

48. Vouret-Craviari, V.; Boquet, P.; Pouysségur, J.; Van Obberghen-Schilling, E. Regulation of the Actin Cytoskeleton by Thrombin in Human Endothelial Cells: Role of Rho Proteins in Endothelial Barrier Function. Mol. Biol. Cell 1998, 9, 2639-2653. [CrossRef] [PubMed]

49. Maiers, J.L.; Peng, X.; Fanning, A.S.; DeMali, K.A. ZO-1 recruitment to $\alpha$-catenin: A novel mechanism for coupling the assembly of tight junctions to adherens junctions. J. Cell Sci. 2013, 126, 3904-3915. [CrossRef] 
50. Bogatcheva, N.V.; Garcia, J.G.; Verin, A.D. Molecular mechanisms of thrombin-induced endothelial cell permeability. Biochemistry 2002, 67, 75-84.

51. Riesen, F.K.; Rothen-Rutishauser, B.; Wunderli-Allenspach, H. A ZO1-GFP fusion protein to study the dynamics of tight junctions in living cells. Histochem. Cell Biol. 2002, 117, 307-315. [CrossRef]

52. Cotrina, M.L.; Lin, J.H.-C.; Nedergaard, M. Adhesive properties of connexin hemichannels. Glia 2008, 56, 1791-1798. [CrossRef]

53. Lin, J.H.-C.; Takano, T.; Cotrina, M.L.; Arcuino, G.; Kang, J.; Liu, S.; Gao, Q.; Jiang, L.; Li, F.; Lichtenberg-Frate, H.; et al. Connexin 43 Enhances the Adhesivity and Mediates the Invasion of Malignant Glioma Cells. J. Neurosci. 2002, 22, 4302-4311. [CrossRef] [PubMed]

54. Xu, X.; Francis, R.; Wei, C.J.; Linask, K.L.; Lo, C.W. Connexin 43-mediated modulation of polarized cell movement and the directional migration of cardiac neural crest cells. Development 2006, 133, 3629-3639. [CrossRef] [PubMed]

55. Kameritsch, P.; Kiemer, F.; Beck, H.; Pohl, U.; Pogoda, K. Cx43 increases serum induced filopodia formation via activation of p21-activated protein kinase 1. BBA Bioenerg. 2015, 1853, 2907-2917. [CrossRef]

56. Wang, X.; Bleher, R.; Brown, M.E.; Garcia, J.G.N.; Dudek, S.M.; Shekhawat, G.S.; Dravid, V.P. Nano-Biomechanical Study of Spatio-Temporal Cytoskeleton Rearrangements that Determine Subcellular Mechanical Properties and Endothelial Permeability. Sci. Rep. 2015, 5, 11097. [CrossRef] [PubMed]

57. Lee, J.-F.; Zeng, Q.; Ozaki, H.; Wang, L.; Hand, A.R.; Hla, T.; Wang, E.; Lee, M.-J. Dual Roles of Tight Junction-associated Protein, Zonula Occludens-1, in Sphingosine 1-Phosphate-mediated Endothelial Chemotaxis and Barrier Integrity. J. Biol. Chem. 2006, 281, 29190-29200. [CrossRef]

58. Grek, C.L.; Montgomery, J.; Sharma, M.; Ravi, A.; Rajkumar, J.; Moyer, K.E.; Gourdie, R.G.; Ghatnekar, G.S. A Multicenter Randomized Controlled Trial Evaluating a Cx43-Mimetic Peptide in Cutaneous Scarring. J. Investig. Dermatol. 2017, 137, 620-630. [CrossRef]

59. Grek, C.L.; Prasad, G.; Viswanathan, V.; Armstrong, D.G.; Gourdie, R.G.; Dvm, G.S.G. Topical administration of a connexin43based peptide augments healing of chronic neuropathic diabetic foot ulcers: A multicenter, randomized trial. Wound Repair Regen. 2015, 23, 203-212. [CrossRef]

60. Ghatnekar, G.S.; Grek, C.L.; Armstrong, D.G.; Desai, S.C.; Gourdie, R.G. The Effect of a Connexin43-Based Peptide on the Healing of Chronic Venous Leg Ulcers: A Multicenter, Randomized Trial. J. Investig. Dermatol. 2015, 135, 289-298. [CrossRef]

61. Montgomery, J.; Ghatnekar, G.S.; Grek, C.L.; Moyer, K.E.; Gourdie, R.G. Connexin 43-Based Therapeutics for Dermal Wound Healing. Int. J. Mol. Sci. 2018, 19, 1778. [CrossRef]

62. Chistiakov, D.A.; Orekhov, A.N.; Bobryshev, Y.V. Endothelial Barrier and Its Abnormalities in Cardiovascular Disease. Front. Physiol. 2015, 6, 365. [CrossRef] [PubMed]

63. Veeraraghavan, R.; Hoeker, G.S.; Alvarez-Laviada, A.; Hoagland, D.; Wan, X.; King, D.R.; Sanchez-Alonso, J.; Chen, C.; Jourdan, J.; Isom, L.L.; et al. The adhesion function of the sodium channel beta subunit ( $\beta 1)$ contributes to cardiac action potential propagation. Elife 2018, 7, e37610. [CrossRef] [PubMed]

64. Veeraraghavan, R.; Lin, J.; Hoeker, G.S.; Keener, J.P.; Gourdie, R.G.; Poelzing, S. Sodium channels in the Cx43 gap junction perinexus may constitute a cardiac ephapse: An experimental and modeling study. Pflügers Arch. Eur. J. Physiol. 2015, 467, 2093-2105. [CrossRef] [PubMed] 